\title{
Development of a Novel Fuzzy Logic-Based Wetland Risk Assessment Approach for the Management of Freshwater Wetland Ecosystems
}

Sajad Soleymani Hasani

University of Tabriz Faculty of Civil Engineering

Alireza Mojtahedi ( $\boldsymbol{\sim}$ a.mojtahed@tabrizu.ac.ir)

University of Tabriz Faculty of Civil Engineering

Mir Amir Mohammad Reshadi

KN Toosi: KN Toosi University of Technology

\section{Research Article}

Keywords: Wetland ecosystem, Wetland management, Risk assessment, Water quality, Fuzzy inference system, Analytic hierarchy process

Posted Date: May 10th, 2021

DOl: https://doi.org/10.21203/rs.3.rs-326933/v1

License: (9) This work is licensed under a Creative Commons Attribution 4.0 International License. Read Full License 


\title{
1 Development of a novel fuzzy logic-based wetland risk assessment 2 approach for the management of freshwater wetland ecosystems
}

\section{Sajad Soleymani Hasani}

Msc. Student, Faculty of Civil Engineering, University of Tabriz, Tabriz, Iran

s.soleymanihasani@gmail.com

Alireza Mojtahedi * (corresponding author)

Associate professor, Faculty of Civil Engineering, University of Tabriz, Tabriz, Iran a.mojtahed@tabrizu.ac.ir

Mir Amir Mohammad Reshadi

Msc. Student, Faculty of Civil Engineering, K. N. Toosi University of Technology, Tehran, Iran a.m.reshadi@email.kntu.ac.ir

\begin{abstract}
In the present study, a new wetland risk assessment approach based on the fuzzy inference system (FIS) was developed and proposed for the first time to improve the traditional ESCOM's wetland classification and risk assessment index (WCRAI). As two of the twenty-five Iranian wetlands of international importance, the Kani Barazan and Choghakhor wetlands were selected as the study areas due to their significant roles in protecting the biodiversity of their regions. The wetlands are supported by the international Ramsar Convention on Wetlands to mandate and encourage the local authorities for their conservation and sustainable exploitation. In this regard, the Iranian Department of Environment, in cooperation with UNDP/GEF, selected these wetlands to demonstrate new approaches to managing the wetland areas protected by the Conservation of Iranian Wetlands Project (CIWP). A real-time wetland monitoring station with hydrological instruments, including water level, air temperature, air humidity, and water quality multi-parameter sensors recording water temperature, $\mathrm{pH}$, specific conductance, and dissolved oxygen, was implanted at the deepest part of both wetlands. The manual sampling of water quality parameters was also carried out periodically during specific time intervals. The relative importance of the wetland health indicators involved in the FIS was determined using the analytic hierarchy process (AHP). In turn, the health level categories of both wetlands were assessed using the traditional and proposed wetland risk assessment approaches. The efficiency of the proposed method was evaluated with the considered scenarios, and it was shown to be a more flexible and appropriate approach for wetland health assessment. Furthermore, the observed differences between the health level categories of the first case study indicated the importance of using the AHP-FIS method to improve the traditional ESCOM's WCRAI.
\end{abstract}

\section{Keywords}

Wetland ecosystem; Wetland management; Risk assessment; Water quality; Fuzzy inference system; Analytic hierarchy process

\section{Highlights}

1. A wetland risk assessment approach based on fuzzy logic was developed.

2. Process was improved using integrated fuzzy inference system and analytic hierarchy process.

3. Two real-time wetland monitoring stations were used to gather the required data.

4. Two freshwater wetlands were selected as real case study areas.

5. The proposed approach showed more flexibility and efficiency. 


\section{Introduction}

Wetlands are among the most valuable and productive ecosystems on the earth. They provide various supporting, provisioning, regulating, and cultural services, all of which make a significant contribution to the well-being of human populations (Thapa et al., 2020; Xu et al., 2020). These delicate ecosystems have been long exposed to unsustainable resource extraction and various anthropogenic activities such as the spread of urbanization, industrialization, and land-use change (Mao et al., 2019; Salimi et al., 2021). Iran has 25 sites designated as wetlands of international importance (Ramsar sites) out of 2,290 worldwide. From 25 sites, about one-third are under pressure or in a critical condition. Although Wetland management in Iran has received more and more attention in recent years, in many instances, these efforts are being held back by the lack of comprehensive assessment tools, insufficient coordination among stakeholders, weak policy and legislative frameworks. The risk assessment of these endangered ecosystems is highly required so that the appropriate management actions to prevent or limit the risk(s) can be carried out in time. As the only intergovernmental treaty, the Ramsar Convention on Wetlands promotes the conservation and wise use of wetlands. The convention has developed a framework for predicting and assessing the changes in ecological characteristics of wetlands and highlighted the role of early warning systems in wetland conservation (Gardner and Finlayson, 2018). Moreover, The U.S. Environmental Protection Agency (USEPA) has proposed a threelevel hierarchical approach, known as the three-tier framework, for wetland assessment and monitoring. This framework ranges from extensive, landscape-scale assessments (level 1), rapid field assessments (level 2) to intensive biological and hydrogeomorphic approaches, termed level 3 (Stryszowska-Hill et al., 2019).

6

In recent years, wetland risk assessment has gained increased attention among scholars, becoming an integral part of sustainable wetland management worldwide. In this regard, various studies, using different indicators and methodologies, have been conducted to evaluate wetland health status and determine the factors threatening these delicate ecosystems. In previous studies, a remote sensing and GIS-based approach, using a set of social and infrastructural indicators, was developed to evaluate the risk level of the East Kolkata Wetland Area in India (Sarkar et al., 2016). In addition, a combination of external threats (natural and artificial hazards) and internal wetland attributes (area, structure, and function) was used to assess the marsh wetlands degradation risk (Jianga et al., 2017). Studies were also conducted considering the significance of social and landscape factors to establish an indicator system for diagnosing wetland health using remote sensing, statistical data, and field sampling (Wu et al., 2018). Additionally, the conservation status of high Andean wetlands was investigated by developing an index that integrates soil, water, biodiversity, and landscape fragmentation indicators (Yepes and Pérez, 2019). Furthermore, the conversion risk assessment of East Kolkata Wetland was carried out using machine learning models, namely, random forest and support vector machine based on population growth and density and a set of proximity factors (Ghosh and Das, 2020). Among various risk assessment approaches, rapid appraisal methods are of particular importance in wetland regulatory and management purposes, as they are easy to implement, less time consuming, and relatively inexpensive. Furthermore, the rapid development of sensor and wireless communication technologies has led 
to the widespread use of automatic sensors in environmental monitoring to address the need for temporally and spatially accurate data for handling complex environmental problems. In this regard, the UNDP Global Environmental Finance (UNDP-GEF) in cooperation with the Conservation of Iranian Wetlands Project (CIWP) selected the Kani Barazan (in local language means "the spring of the hogs") and Choghakhor (in local language means "the sun hill") wetlands as hotspot sites to demonstrate new approaches to the management of Iran's wetland protected areas. A real-time wetland monitoring station equipped with hydrological instruments was installed within the wetland regions by order of CIWP. The station uses a Blue Box modular for transferring the measured data via a website to the database. Such systems provide a large amount of data, which poses challenges for ensuring data quality; thereby, highlighting the role of appropriate data-mining tools. However, rapid appraisal methods use a finite set of field measurements and indicators to assess the ecological conditions of wetlands. These approaches have proven to be fruitful in providing reliable and quantitative information on the overall health status of wetlands (Fennessy et al., 2004; Stein et al., 2009), one of which is the ESCOM's wetland classification and risk assessment index (WCRAI) developed by Oberholster et al. (2014). This traditional index, which involves various water quality variables and physical characteristics of wetlands, was successfully applied to several wetlands in South Africa. However, most rapid risk assessment indices lack the capability to deal with uncertainties and subjectivity associated with these complex environmental problems. In this sense, fuzzy logic has emerged as a robust way of dealing with vague, incomplete, and inconsistent information (Abdel-Basset and Mohamed, 2018; de Oliveira et al., 2019; Seyedmohammadi et al., 2018). Fuzzy logic developed on fuzzy set theory allocates a degree of membership, generally a value between zero and one, to elements of a universe of discourse (Oladipo et al., 2021). Where zero represents "no membership" or "totally false," and one represents "full membership" or "totally true." It has been shown that the linguistic computations conducted in a fuzzy inference system (FIS) are superior to common algebraic expressions and provide more realistic results when dealing with environmental problems (Lermontov et al., 2009; Ocampo-Duque et al., 2013). The successful application of a FIS depends on proper weight assignment to the fuzzy rules (Ocampo-Duque et al., 2006). In this regard, researchers from different disciplines, including water quality and wetland health studies, have used the analytic hierarchy process (AHP) as a reliable approach for weighting variables included in a FIS (Al Mamun et al., 2019; Ávila-Flores et al., 2020; Hu et al., 2021; Srđević et al., 2020). The AHP is a robust multi-objective mathematical method developed by Saaty (2003), which explicitly ranks tangible and intangible criteria against each other by making pairwise comparisons between them (Sun et al., 2019).

Until the past few years, there have been relatively few investigations dealing with real-time and water quality data to assess wetlands within arid and semi-arid regions. The development of time-series data mining techniques has provided an emerging method for wetland health assessment. This paper aims to propose a novel framework for wetland health assessment considering real case studies. In this regard, a fuzzy logicbased wetland risk assessment approach (FLWRAA) was developed and proposed to introduce fundamental improvements to the non-fuzzy ESCOM's WCRAI. This traditional non-fuzzy index was developed using an 
unweighted set of parameters, where crisp sets were used to divide their ranges. The problem associated with crisp sets is that they fail to handle the epistemic uncertainty that arises from the limits of our knowledge about natural systems. Furthermore, equally valued (unweighted) parameters lead to imprecise results since parameters such as dissolved oxygen (DO) and electrical conductivity (EC) play a vital role in aquatic ecosystems; therefore, they should be regarded with higher importance. To deal with these limitations, a FIS, combined with the AHP methodology, was integrated with this traditional index to provide a more flexible and reliable approach for wetland health assessment. In this regard, crisp sets were superseded by fuzzy sets, and the AHP method was used to assign weights to wetland health indicators. This rapid assessment method holds a central position in monitoring programs because once established, it can provide sound and quantitative information on wetland health status with a relatively small investment of time and effort. The applicability of the proposed approach has been evaluated by applying it to the Kani Barazan and Choghakhor Ramsar sites, the Iranian wetlands with international importance, and comparing the achieved results to that of the ESCOM's WCRAI.

\section{Materials and Methods}

\subsection{Rapid risk assessment index}

Increases in the need for effective wetland assessment and monitoring programs have resulted in numerous rapid appraisal methods. Among them, the ESCOM's WCRAI is a reliable approach to determine the overall wetland health status, which can be implemented by non-wetland experts (Wanda et al., 2016). This index involves field sampling and in situ measurement of some water physicochemical parameters, including DO, $\mathrm{EC}$, and $\mathrm{pH}$, which are described in section 2.3.3, as well as various physical characteristics of the wetland. Data collection on the wetland's physical characteristics consists of investigating soil, fringing vegetation, and aquatic vegetation of the area. These parameters are listed in Table 1.

Table 1. Physical characteristics used in the wetland health assessment

\begin{tabular}{ll}
\hline Indicator & Description \\
\hline Aquatic vegetation cover & $\begin{array}{l}\text { The percentage of the water surface covered with aquatic } \\
\text { vegetation, including emergent, submerged, and floating plants, } \\
\text { was estimated visually. }\end{array}$
\end{tabular}

Attached algae

Spatial heterogeneity of macrophytes

Width of fringing vegetation
The relative abundance of macroalgae, as an indicator of the trophic status of wetlands, was measured using the rapid appraisal method proposed by Oberholster et al. The categories used for the index are represented in Table 2.

The number of layers of aquatic vegetation was assessed according to Oberholster et al. and Spencer et al., where the following five macrophyte layers were included: (i) free-floating at the surface, (ii) free-floating beneath the surface, (iii) emergent, (iv) in the substrate with floating leaves, and (v) submerged.

The mean width of fringing vegetation was determined based on visual estimations of the riparian vegetation strip at four parts of the wetland.
Reference

(Oberholster et al., 2014)

(Oberholster et al., 2010; Spencer et al., 1998) 
Degree of bank stability

Degree of pugging
The degree of bank stability was assessed visually following a walk throughout the whole study area. The categories used for the index are listed in Table 2.

Degree of pugging: The mean number of animal hoof marks was determined according to Spencer et al., where ten $1-\mathrm{m}^{2}$ quadrants were randomly placed on the sediment surface at the wetland's edge.
(Spencer et al., 1998)

Table 2. Scoring categories for the abundance of attached algae and degree of bank stability (Oberholster et al., 2014)

The abundance of attached algae

\begin{tabular}{ll}
\hline Description & Category \\
\hline Mats of microalgae present $>1.0 \mathrm{~m}^{2}$ & 0 \\
Clumps or mats of drifting microalgae present $\left(0.51-1.0 \mathrm{~m}^{2}\right)$ & 1 \\
Microalgae present $\left(0.11-0.5 \mathrm{~m}^{2}\right)$ & 2 \\
Microalgae present $\left(0.01-0.1 \mathrm{~m}^{2}\right)$ & 3 \\
Absence of algae mats & 4 \\
\hline
\end{tabular}

Degree of bank stability

\section{Description}

Category

Wetland banks are stable and well protected by vegetation cover

High $=4$

Some minor spot erosion occurring or areas of limited vegetation

Moderately high $=3$

Some erosion occurring, spot erosion points are often interlinked, and

Medium $=2$ possibly minor structural and vegetation damage

Significant areas of erosion occurring, little vegetation present

Moderately low $=1$

Extensive erosion occurring, bare banks, steep or undercut banks

Low $=0$

In order to facilitate the measurements, and considering the fact that different parts of the selected wetlands are exposed to different anthropogenic activities, including agricultural activities, wastewater disposal, tourism, and livestock grazing, they were divided into four parts, and the results obtained from these parts were averaged to calculate the overall values. The optimized ranges for scoring the described indicators as well as the physicochemical parameters of water, which are described in section 2.3.2, are shown in Table 3. After scoring all indicators, they are added to calculate the total score, ranging from zero to thirty-six. The overall score is transferred to a percentage to determine the wetland's ecological status based on categorical variables. More detailed information can be found in Oberholster et al. (2014).

Table 3. The ESCOM's WCRAI scoring ranges for wetland health indicators (Oberholster et al., 2014)

\begin{tabular}{|c|c|c|c|c|c|c|}
\hline \multirow{2}{*}{ Indicator } & \multirow{2}{*}{ Unit } & \multicolumn{5}{|c|}{ Score Range } \\
\hline & & 4 & 3 & 2 & 1 & 0 \\
\hline Dissolved oxygen & $\mathrm{mg} / \mathrm{l}$ & $>7$ & $5.01-7.0$ & $2.01-5.0$ & $1.5-2.0$ & $<1.5$ \\
\hline $\begin{array}{l}\text { Electrical conductivity (non- } \\
\text { pans) }\end{array}$ & $\mu \mathrm{S} / \mathrm{cm}$ & $0-292$ & $293-833$ & $834-2500$ & $2501-5833$ & $>5833$ \\
\hline Electrical conductivity (pans ${ }^{a}$ ) & $\mu \mathrm{S} / \mathrm{cm}$ & $0-418$ & $419-2450$ & $2451-7832$ & $7833-11600$ & $>11600$ \\
\hline $\mathrm{pH}$ & & $7.01-7.5$ & $6.61-7.0$ & $6.21-6.6$ & $6.0-6.2$ & $<6$ or $>8$ \\
\hline
\end{tabular}




\begin{tabular}{lcccccc} 
& \multicolumn{7}{c}{$7.51-8.0$} & \\
Width of fringing vegetation & $\mathrm{m}$ & $>30$ & $8-30$ & $3-7.9$ & $0.5-2.9$ & $<0.5$ \\
$\begin{array}{l}\text { Degree of bank stability } \\
\text { Degree of pugging }\end{array}$ & & High & Moderately high & Medium & Moderately low & Low \\
$\begin{array}{l}\text { Aquatic vegetation cover } \\
\text { Spatial heterogeneity of }\end{array}$ & $\%$ & $41-65$ & $26-40$ & $5-25$ & $>65$ & $<5$ \\
macrophytes & $\#$ & $>3$ & 3 & 2 & $13-19$ & 0 \\
Attached algae & $\mathrm{cm}^{2}$ & 0 & $1-1000$ & $1001-5000$ & $5001-10000$ & $>10000$ \\
\hline
\end{tabular}

${ }^{a}$ Small depression with an inward draining flow pattern and no outflow.

\subsection{Development of the fuzzy logic-based wetland risk assessment approach (FLWRAA)}

The traditional non-fuzzy wetland risk assessment indices inherit several weaknesses, leading to imprecise and subjective results. Most indices use crisp sets that cannot deal with the epistemic uncertainty involved in these complex environmental problems. Moreover, such indices do not consider the relative importance of the parameters, i.e., they do not employ weighted parameters. In turn, some parameters with relatively less importance can dramatically influence the final score. However, the need for more flexible and appropriate methods to assess the wetland health level (WHL) is clearly recognized.

\subsubsection{Fuzzy inference system}

Fuzzy set theory has been successfully used to deal with the ambiguity and uncertainty involved in complex environmental problems. As opposed to crisp sets, fuzzy logic provides sets with vague boundaries whose elements are defined with degrees of membership. They can be used for mapping a set of inputs to an appropriate set of outputs. Fig. 1 illustrates an input-output map for the wetland health classification problem using a given set of wetland health indicators.

Mamdani fuzzy inference method has been shown to be the most commonly used fuzzy inference system (Al Mamun et al., 2019; Komsiyah and Desvania, 2021). It provides easier to interpret and understand rule bases, specifically when rules are generated based on human knowledge. The development of a fuzzy inference system includes five main stages that are briefly described below.

a) Fuzzification: Fuzzification includes the definition of input and output variables as well as the determination of the membership functions (MFs) that transform the crisp values of variables into appropriate fuzzy sets through membership grades.

b) Rule combination: In this step, membership values are combined to obtain a single value that represents the result of multiple-part antecedents. The combining process is mainly done by applying fuzzy operators, namely, AND, OR, and NOT.

c) Weighting: Since the rules vary in importance, a weight, typically a number between 0 and 1 , is assigned to each one to determine the relative effect of each input variable in the final score. The weighting methodology used in this study is the analytic hierarchy process, which is described in section 2.2.2. 
d) Implication and aggregation: During the implication process, the consequence of a rule, which is a fuzzy set, is determined by calculating the fulfillment degree of the rule. Aggregation is the process of combining the outputs of all fuzzy rules, which were previously generated by the implication process, to produce a single fuzzy set for each output variable.

e) Defuzzification: Finally, the fuzzy inference output is defuzzified to obtain a single non-fuzzy crisp value for each output. The center of area (COA) has been shown to be the most widely used defuzzification method (Mojtahedi et al., 2020; Shwetank et al., 2020; Wang, 2001).
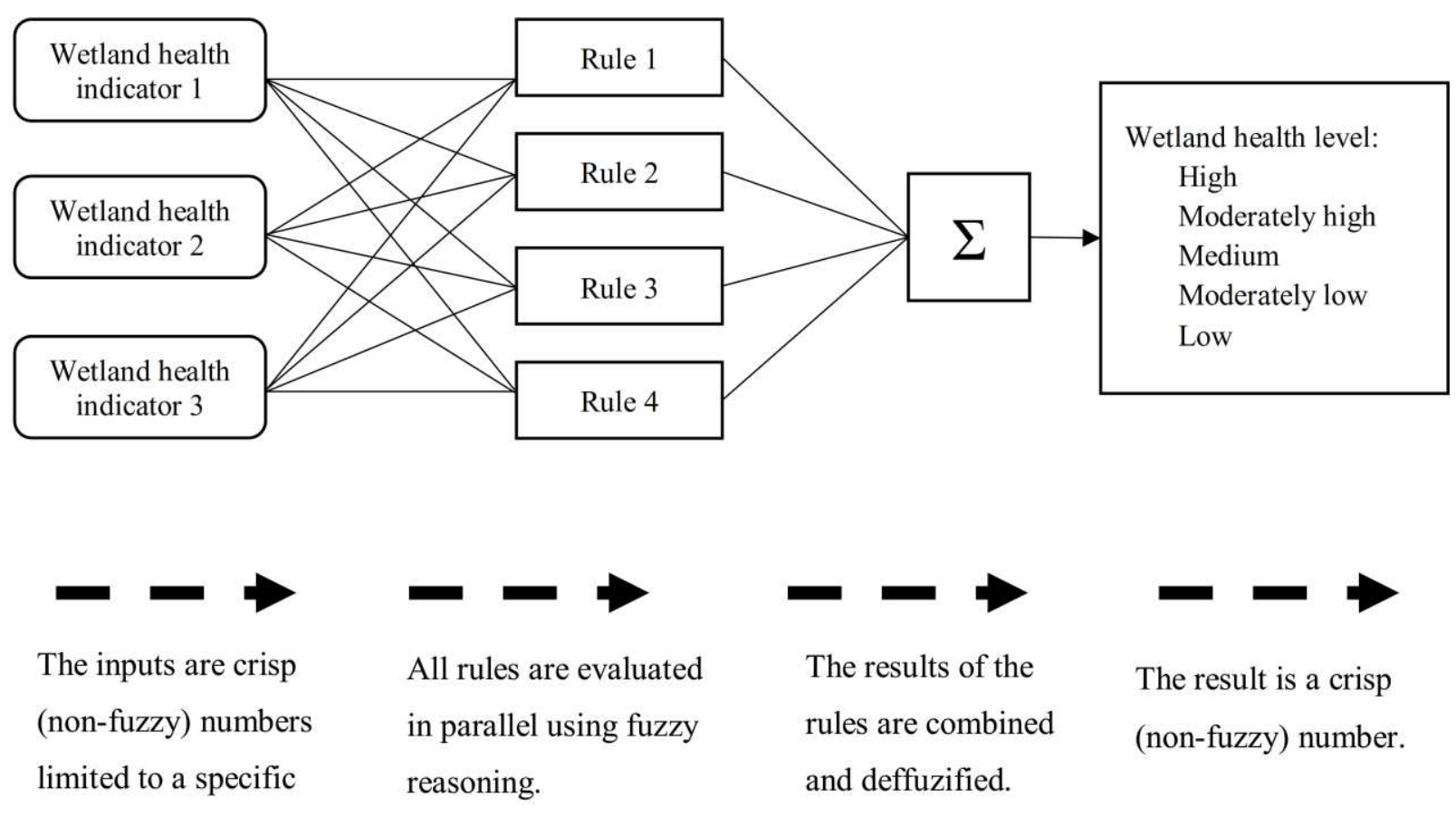

The result is a crisp (non-fuzzy) number.

Fig. 1. Input-output map for the wetland health level problem in a fuzzy inference system.

\subsubsection{The analytic hierarchy process}

Since the efficiency of a FIS is concerned with the rule weights, an appropriate approach for weight assignment is highly required. The weighting methodology used in this study is the AHP developed by Saaty (2003). The AHP is a robust and widely used multi-criteria decision-making tool that solves the problem by prioritizing the alternatives. It arranges the problem into three general hierarchical levels, including the goal, criteria, and alternatives (Hu et al., 2021). The prioritization of the elements is carried out through pairwise comparisons. For this reason, the components of each level are transferred into a $n \times n$ reciprocal matrix $A=\left[a_{i j}\right]_{n \times n}$, where aij elements of $A$ represent the numerical estimates made by the decision-maker using a 1-9 scoring range (Table 4).

Table 4. The AHP comparison scales (Saaty, 2001)

\begin{tabular}{lll}
\hline Intensity of importance & Definition & Explanation \\
\hline 1 & Equal Importance & $\begin{array}{l}\text { Two activities contribute equally to the } \\
\text { objective }\end{array}$ \\
3 & Moderate importance & $\begin{array}{l}\text { Experience and judgment slightly favor } \\
\text { one activity over another }\end{array}$
\end{tabular}


Extreme importance

An activity is favored very strongly over another; its dominance demonstrated in practice

The evidence favoring one activity over another is of the highest possible order of affirmation

$2,4,6,8$

Reciprocals
Intermediate values between the two adjacent When compromise is needed judgment

If activity $i$ has one of the above non-zero numbers assigned to it when compared with activity $\mathrm{j}$, then $\mathrm{j}$ has the reciprocal value when compared with $\mathrm{i}$

Ratios arising from the scale
If consistency is to be forced by obtaining $\mathrm{n}$ numerical values to span the matrix

193 In this matrix, elements of the main diagonal $\left(a_{i i}\right)$ denote the same pair of components; hence, they equal 1, 194 and the symmetrical elements are mutually reciprocal (Eq. 1).

$a_{i j}=\frac{1}{a_{j i}}, a_{i j}>0, i, j=1,2, \ldots, n$.

195 Therefore, the matrix $A$ is built up of $n(n-1) / 2$ judgments. The goal is to find a vector of priorities $w=\left[w_{1}, w_{2}, \ldots, w_{n}\right]^{T}$, with the normalized components (Eq. 2):

$\sum_{i=1}^{n} w_{i}=1, w_{i}>0, i=1,2, \ldots, n$

197 where the $n \times n$ matrix of ratios $W=\left[w_{i} / w_{j}\right]_{n \times n}$ approximates the comparison matrix $A$. Matrix $A$ is 198 consistent if (Eq. 3):

$a_{i j}=\frac{u_{i}}{u_{j}}, u_{i}>0, i, j=1,2, \ldots, n$.

199 A consistent matrix naturally satisfies the transitivity relation (Eq. 4):

$a_{i k}=a_{i j} a_{j k}, i, j, k=1,2, \ldots, n$.

200 Also, every element of the consistent matrix $A$ can be determined from its first row, since (Eq. 5):

$a_{i k}=\frac{a_{1 k}}{a_{1 i}}, i, k=1,2, \ldots, n$.

201 Therefore, $A$ is a rank-one matrix with exactly one non-zero eigenvalue $\lambda=n$, where (Eq. 6):

$A u=n u$

202 Finally, the normalized eigenvector $w=\left[w_{1}, w_{2}, \ldots, w_{n}\right]^{T}$, with the components (Eq. 7): 
$w_{i}=\frac{u_{i}}{\sum_{j=1}^{n} u_{j}}, j=1,2, \ldots, n$

203 can be determined.

204 To ensure consistency of the judgments, a consistency check must be applied (Eq. 8):

$C I=\frac{\lambda_{\max }-n}{n-1}$

205 where $C I$ is the consistency index and $\lambda_{\max }$ is the largest eigenvalue. In turn, the consistency ratio $(C R)$ can be determined as (Eq. 9):

$C R=\frac{C I}{R I}$

where $R I$ is the random index that can be elicited from Table 5. If $C R$ is less than 0.10 , then the matrix $A$ is considered consistent; otherwise, the judgments should be revised (Andrecut, 2014; Saaty, 2001).

Table 5. Random indices from Saaty (2004)

\begin{tabular}{lllllllllll}
\hline$n$ & 1 & 2 & 3 & 4 & 5 & 6 & 7 & 8 & 9 & 10 \\
\hline$R I$ & 0 & 0 & 0.52 & 0.89 & 1.11 & 1.25 & 1.35 & 1.40 & 1.45 & 1.49 \\
\hline
\end{tabular}

\subsubsection{Framework for the assessment of wetland health level using the fuzzy logic system}

In this study, a fuzzy logic-based approach for evaluating wetland health level has been developed. For this purpose, nine parameters, classified into three groups, are used to assess the overall wetland health. These groups are as follows:

- Group 1 (physicochemical parameters of water): DO, EC, and $\mathrm{pH}$.

- Group 2 (aquatic vegetation): aquatic vegetation cover, attached algae, and spatial heterogeneity of aquatic vegetation.

- Group 3 (soil and fringing vegetation): width of fringing vegetation, degree of bank stability, and degree of pugging.

Trapezoidal and triangular membership functions (MFs) were used to represent the input and output variables. It has been shown that trapezoidal and triangular MFs yield more efficient computations in practical applications and can characterize the dynamic behavior of environmental indicators such as water quality parameters (Bilgiç and TürkŞen, 2000; Dutta and Ali, 2012; Nasseri, 2008; Oladipo et al., 2021). In this study, Five fuzzy sets, namely "low," "moderately low" (ML), "medium," "moderately high" (MH), and "high," were used to split the inputs and outputs, except for pH, which two more sets ("slightly low" (SL) and "very low" (VL)) were required to cover the whole scoring range (Fig. 2). 

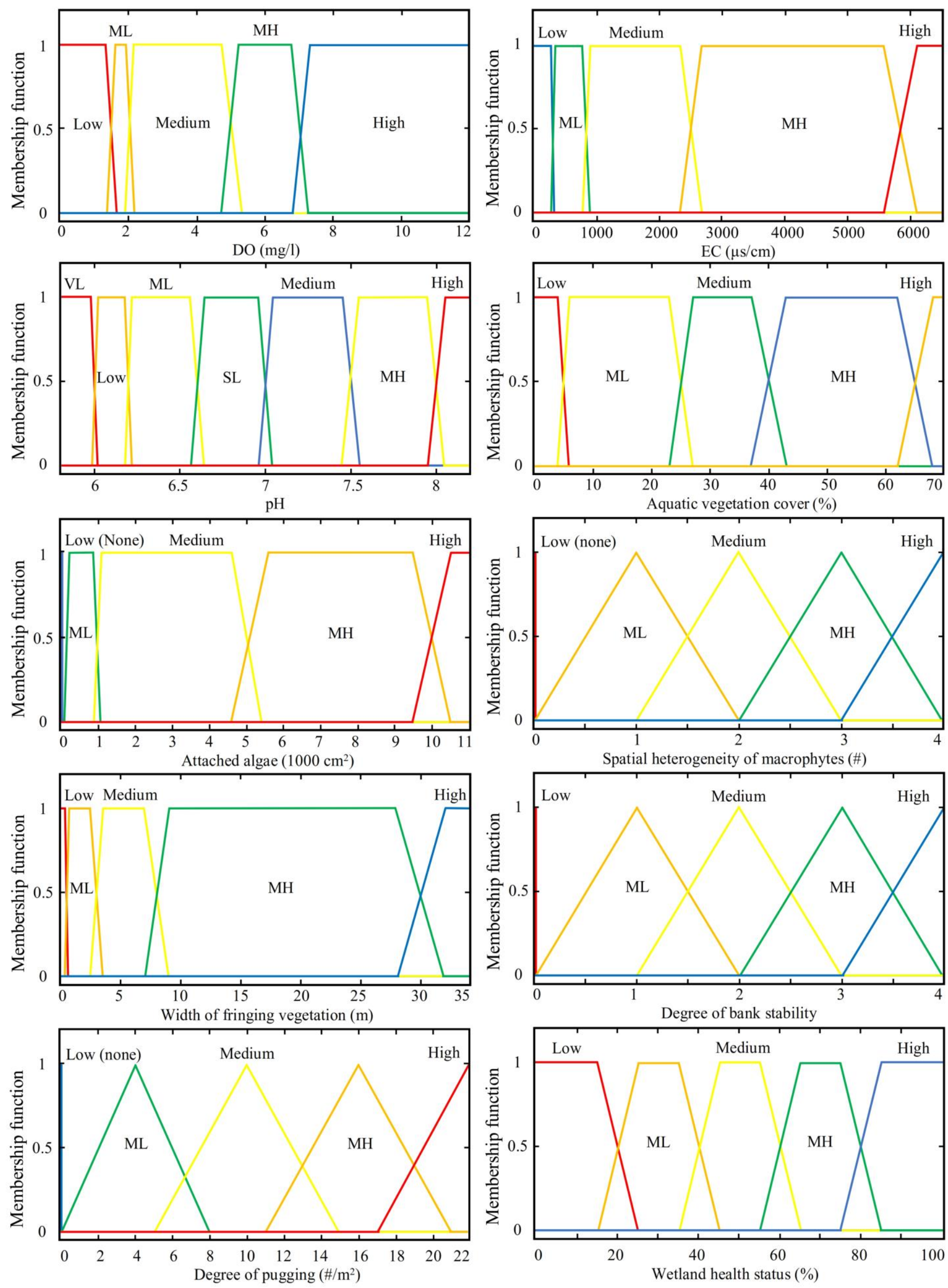

Fig. 2. Linguistic variables and membership functions of the input and output variables 


$$
\begin{aligned}
& f(x ; a, b, c, d)=\max \left(\min \left(\frac{x-a}{b-a}, 1, \frac{d-x}{d-c}\right), 0\right) \\
& f(x ; a, b, c)=\max \left(\min \left(\frac{x-a}{b-a}, \frac{c-x}{c-b}\right), 0\right)
\end{aligned}
$$

Where $a, b, c$, and d represent the membership function parameters. Ranges for fuzzy sets were based on the ranges of the ESCOM's wetland risk assessment index.

Sixty rules were defined, five for each indicator and five for each group of indicators. In order to facilitate the weight assignment, each rule had only one antecedent. Fuzzy rules were mainly based on two structures, but there were exceptions for $\mathrm{pH}$ and the aquatic vegetation cover. The fuzzy rule structures are shown in Table 6. The rules for DO, the width of fringing vegetation, degree of bank stability, and the number of macrophyte layers were based on structure I (positive correlation). While the rules for EC, degree of pugging, and the abundance of attached algae followed structure II (negative correlation). The fuzzy rules for $\mathrm{pH}$ and aquatic vegetation cover did not follow any of these structures and were based on exclusive structures. Experts with either academic or field experience in wetland studies were consulted to ensure the fuzzy rules' appropriate weighting. The framework of FLWRAA is shown in Fig. 3.

Table 6. The fuzzy rules for wetland health indicators. (a) Structure I; (b) Structure II; (c) pH; (d) Aquatic vegetation cover

\begin{tabular}{|c|c|c|c|}
\hline If indicator $i$ is & $\begin{array}{l}\text { a) high } \\
\text { b) moderately high } \\
\text { c) medium } \\
\text { d) moderately low } \\
\text { e) low }\end{array}$ & then wetland health level is & $\begin{array}{l}\text { a) high } \\
\text { b) moderately high } \\
\text { c) medium } \\
\text { d) moderately low } \\
\text { e) low }\end{array}$ \\
\hline
\end{tabular}

(a) Structure I (positive correlation)

\begin{tabular}{|c|c|c|c|}
\hline If indicator $i$ is & $\begin{array}{l}\text { a) low } \\
\text { b) moderately low } \\
\text { c) medium } \\
\text { d) moderately high } \\
\text { e) high }\end{array}$ & then wetland health level is & $\begin{array}{l}\text { a) high } \\
\text { b) moderately high } \\
\text { c) medium } \\
\text { d) moderately low } \\
\text { e) low }\end{array}$ \\
\hline
\end{tabular}

(b) Structure II (negative correlation)

(c) $\mathrm{pH}$ 


\begin{tabular}{lll}
\hline If $\mathrm{pH}$ is & then wetland health level is & a) high \\
& a) medium slightly low & b) moderately high \\
c) moderately low or & c) medium \\
moderately high & d) moderately low \\
d) low & e) low \\
e) very low or high &
\end{tabular}

(d) Aquatic vegetation cover

\begin{tabular}{|c|c|c|c|}
\hline $\begin{array}{l}\text { If aquatic vegetation } \\
\text { cover is }\end{array}$ & $\begin{array}{l}\text { a) moderately high } \\
\text { b) medium } \\
\text { c) moderately low } \\
\text { d) high } \\
\text { e) low }\end{array}$ & then wetland health level is & $\begin{array}{l}\text { a) high } \\
\text { b) moderately high } \\
\text { c) medium } \\
\text { d) moderately low } \\
\text { e) low }\end{array}$ \\
\hline
\end{tabular}

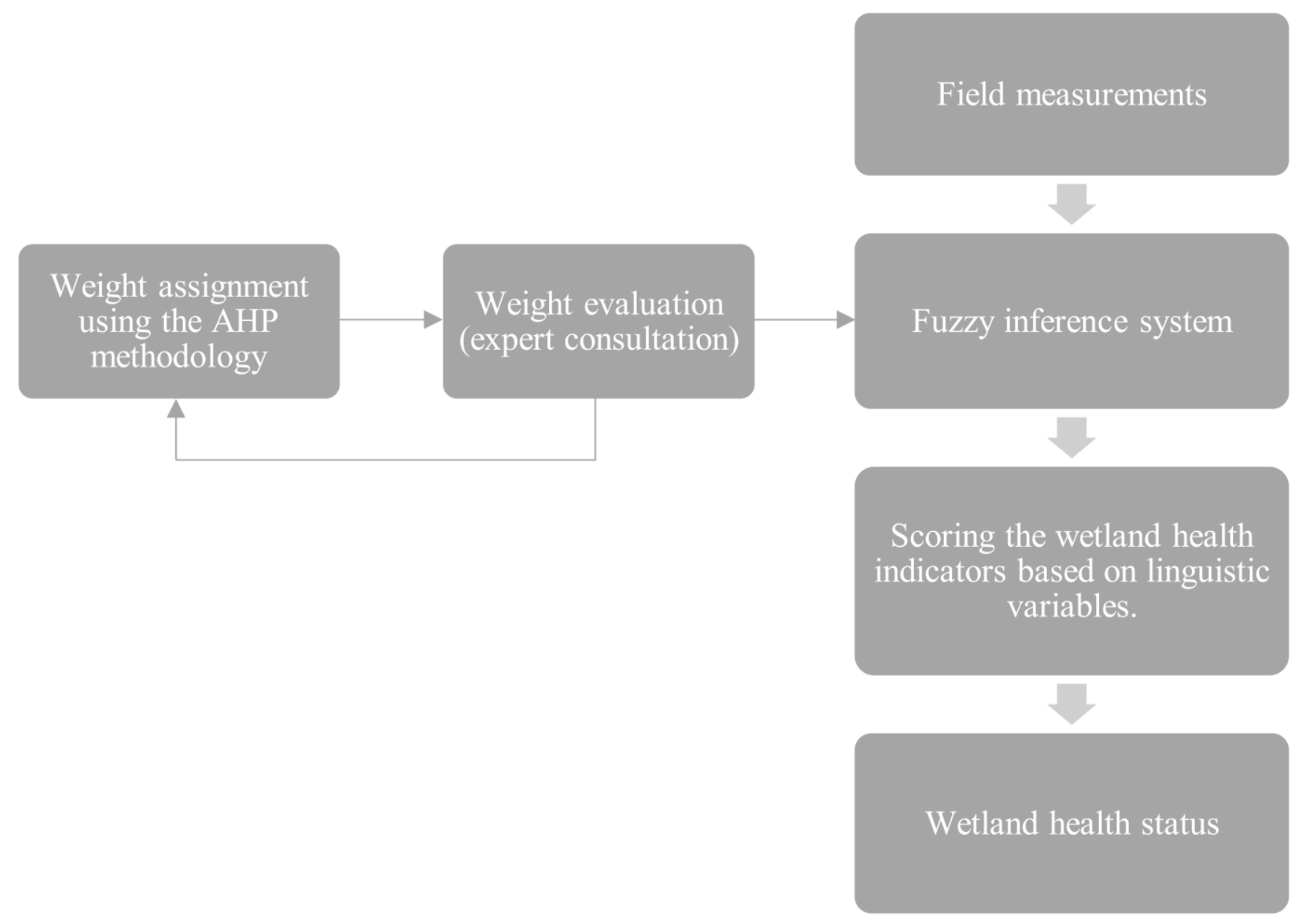

Fig. 3. The framework of the fuzzy logic-based wetland risk assessment approach

\subsubsection{Case study}

\section{(a) The Kani Barazan wetland in northwest Iran}

The Kani Barazan (in local language means "the spring of the hogs") wetland, as part of the southern ecology of Lake Urmia, encompasses an area of approximately 900 hectares and is located along the northern part of Mahabad city ( $36^{\circ} 59^{\prime} 32^{\prime \prime}$ latitude North and $45^{\circ} 46^{\prime} 32^{\prime \prime}$ longitude East) in the province of West Azerbaijan, Iran (Fig. 4). The wetland is supplied by the Mahabad dam and its downstream river. The area experiences a semi-arid climate with distinct seasons. The annual average rainfall is $410 \mathrm{~mm}$, with the most precipitation falling from October to May. Regarding its unique geological characteristics, the Kani Barazn wetland was 
added to the list of Ramsar sites in 2011 and recorded as the first Iranian birdwatching site home to various indigenous and migratory species (Mansouri and Majnoni, 2014). Based on Escom's WCRAI (Oberholster et al., 2014), this area can be categorized as a hillslope seepage wetland. Water quality in the Kani Barazan wetland is monitored with an online monitoring station (Fig. 5) established in 2019 as a part of the Conservation of Iranian Wetlands Project (CIWP). The CIWP started as a joint initiative between the Government of Iran, Global Environmental Facility (GEF), and the United Nations Development Program (UNDP) to enhance the sustainability of Iran's protected wetland areas and preserve their globally-significant biodiversity (Ruzbahani and Manager, 2013). The online monitoring station regularly measures the DO, EC, $\mathrm{pH}$, water temperature, water level, and meteorological parameters such as air pressure and temperature. Consequently, this station was selected as one of the four water sampling points.

\section{(b) The Choghakhor wetland in the central west of Iran}

The Choghakhor (in local language means "the sun hill") wetland in the south of Shahr-e Kord, Chaharmahal and Bakhtiari province ( $31^{\circ} 55^{\prime} 23^{\prime \prime}$ latitude North, 50 53' 59" longitude East) is located at the northern slopes of Kallar mountain (Fig. 4). The topography of the region is such that the plain formed by the mountains "Baraftab" in the north, "Shapurnaz" in the west, and "Kallar" from the west to the south has created a drainage basin of 114 square kilometers as a suitable location to feed a wetland with a surface area of about 1500 hectares. The main water sources for this water body of 44-46 million cubic meters are upstream rainfall of the drainage basin, numerous springs, and groundwater flow due to snowmelt in warm seasons. Due to the wetland's location in the Zagros mountain range, various factors such as the presence of a high-pressure belt cause significant changes in the region's climate during the year. As a result, when the belt shifts to lower latitudes in hot seasons, rainfall decreases, and in winter, when the belt shifts to the Persian Gulf, it provides suitable conditions for the entry of western cyclones and subsequent increase in rainfall. Annual precipitation in the wetland varies from 500 to $750 \mathrm{~mm}$.

Based on the ESCOM's WCRAI (Oberholster et al., 2014), this area can be categorized as a permanently inundated lake wetland. The Choghakhor wetland is known as one of the Important Bird Areas (IBA) for it is the habitat of a wide range of animals and plants, including more than 20 bird species ( 2 endangered species). Also, in 2011, Choghakhor was listed as a Ramsar site according to its international importance (Ramsar Convention, 2020). Providing a safe water source along with flood control are some of the services that this wetland has provided to encompassing populations. Like other Ramsar sites under the protection of the CIWP, the Choghakhor wetland is equipped with an online monitoring station that was established and connected to the central server present at CIWP headquarters in 2018 (Fig. 5). The station continuously measures various parameters, including DO, EC, and $\mathrm{pH}$ at three different levels $(0.3,0.85$, and 1.4 meters), water temperature, water level, and meteorological parameters such as air pressure, temperature, and humidity. The station was chosen as one of the four periodic water sampling points. 


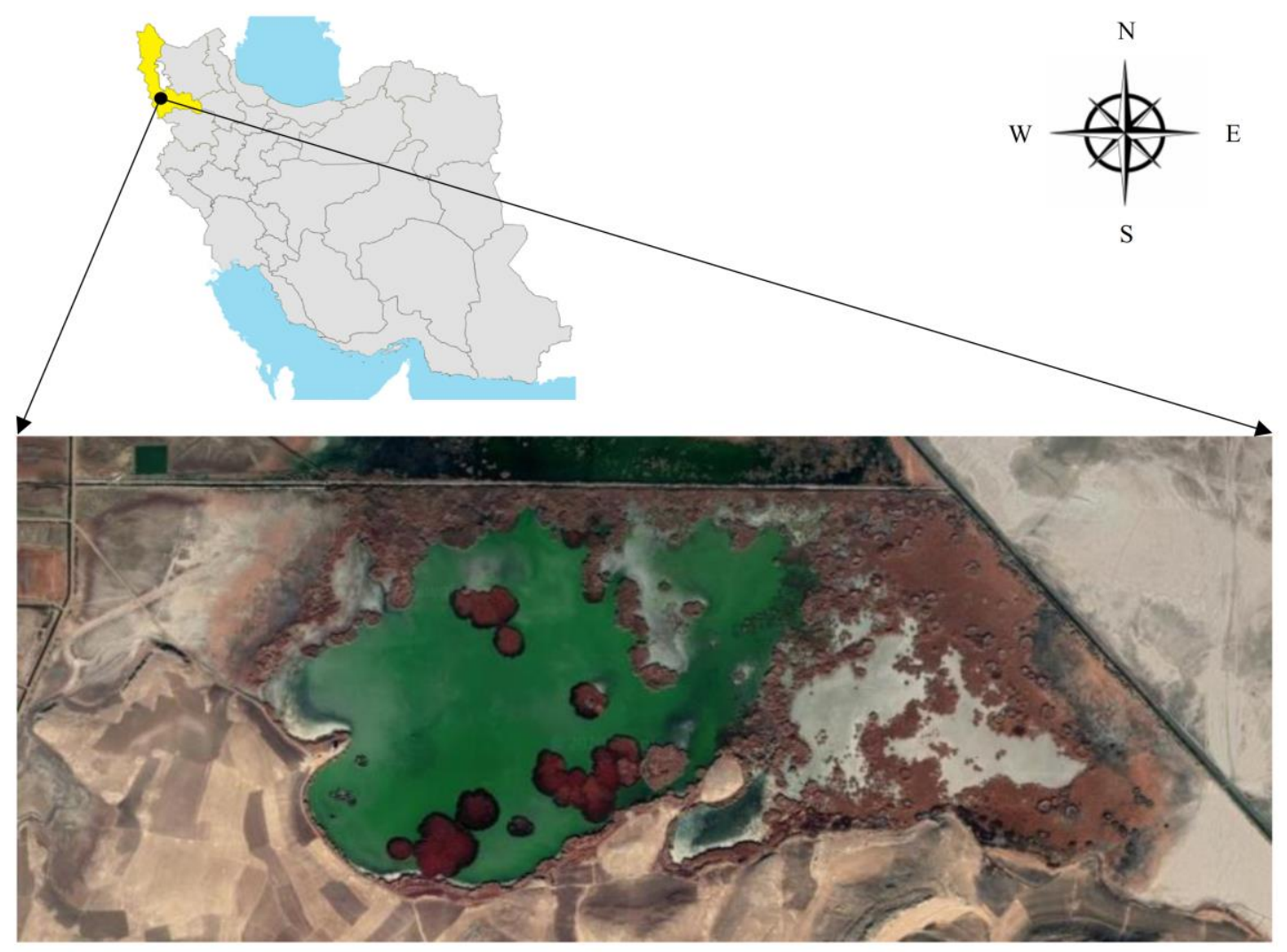

(a) Satellite view of the Kani Barazan wetland

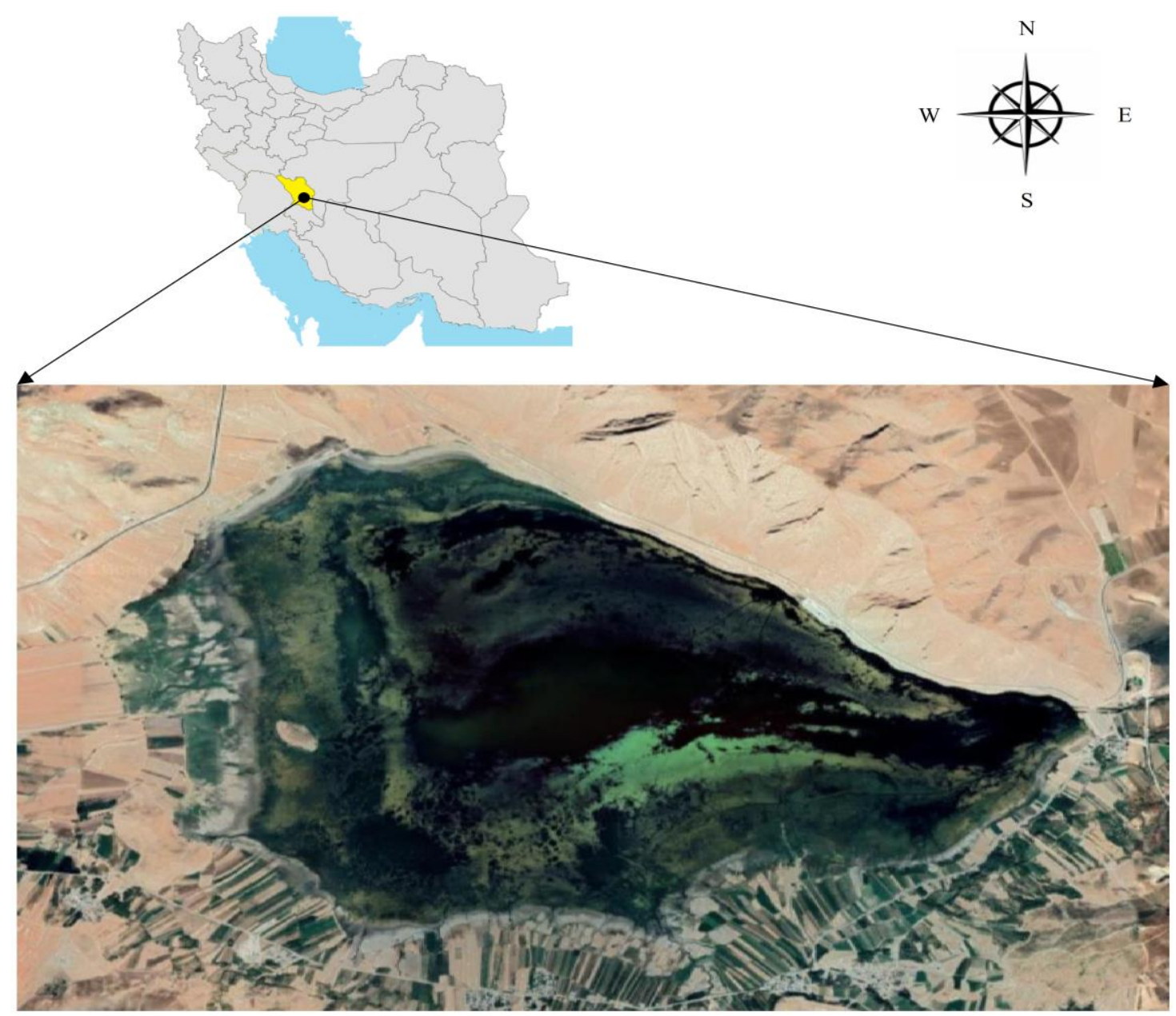

Fig. 4. (b) Satellite view of the Choghakhor wetland 


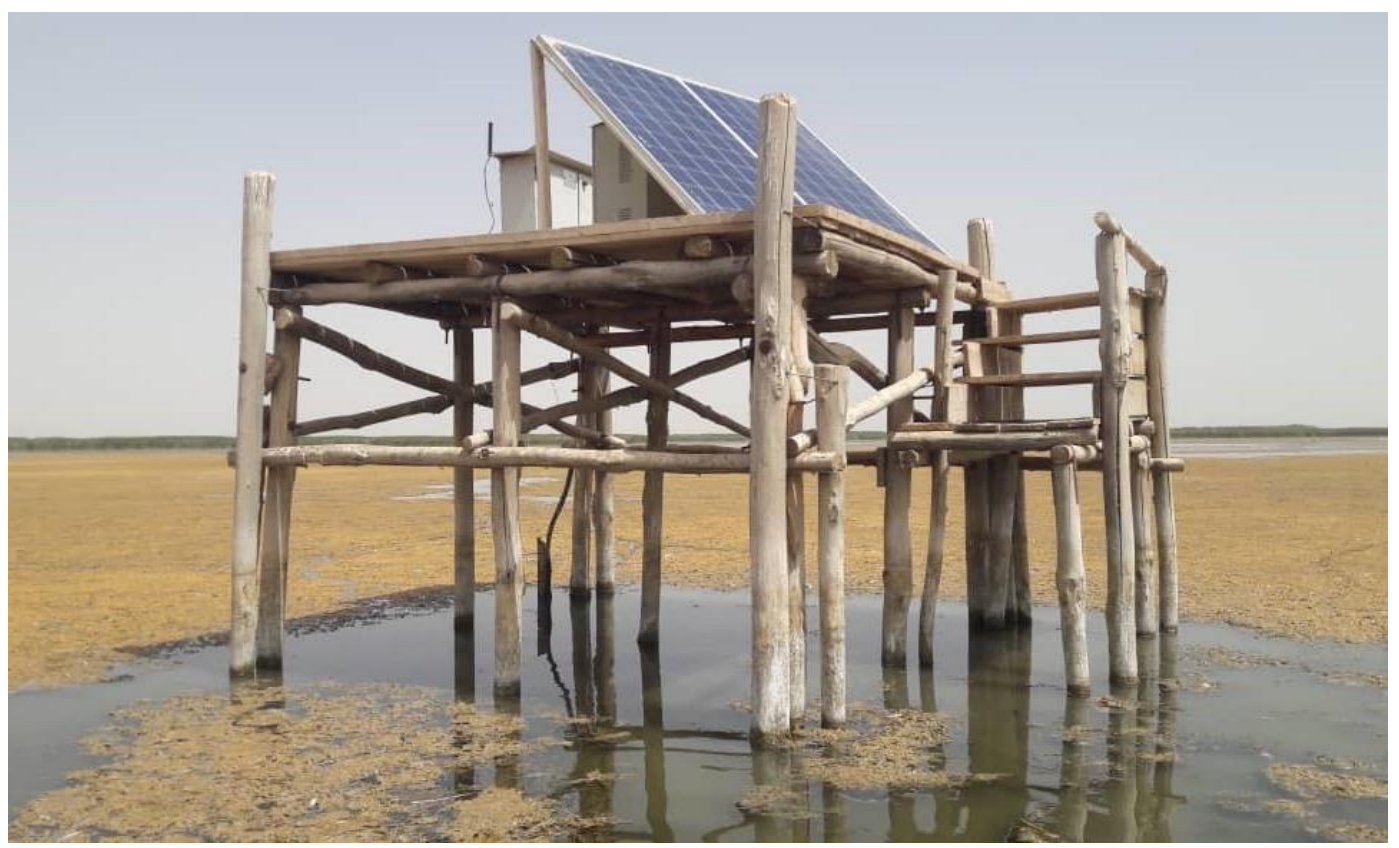

(a) The online monitoring station in the Kani Barazan wetland

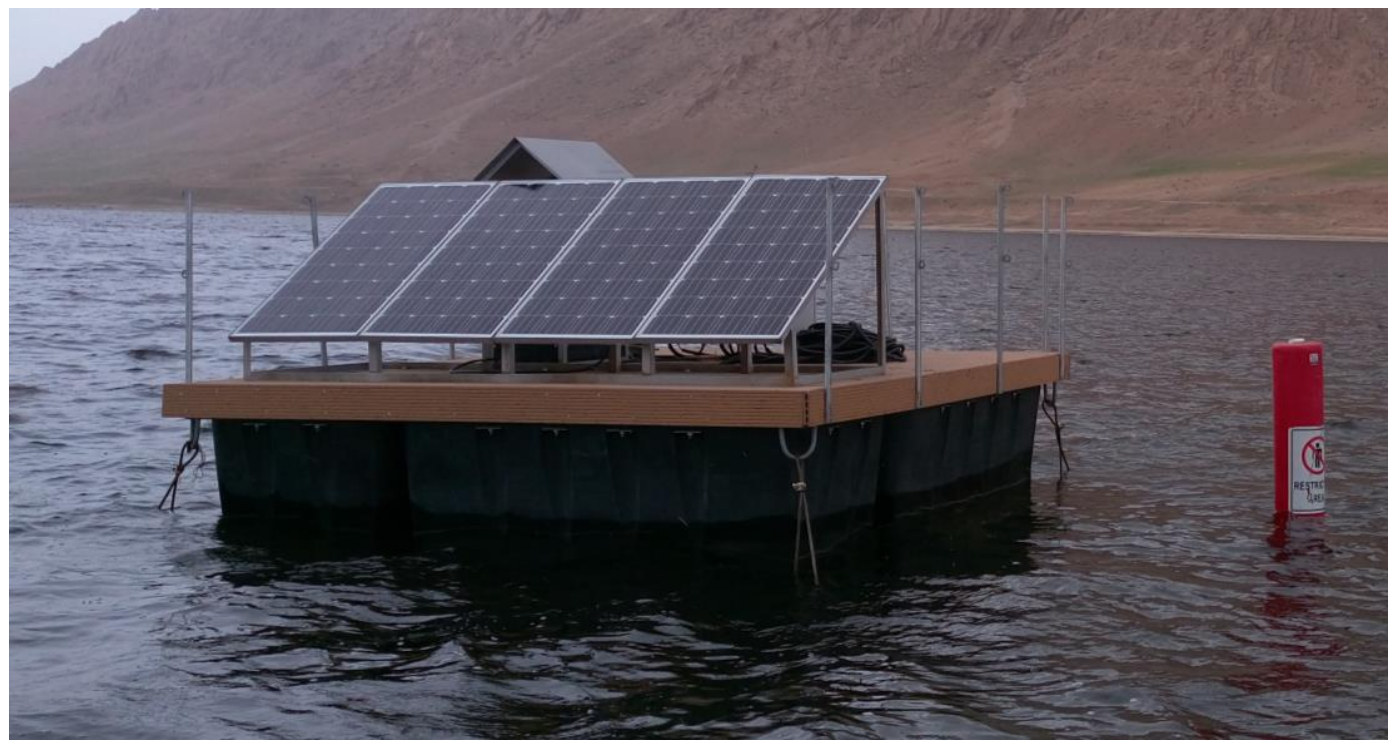

Fig. 5. (b) The online monitoring station in the Choghakhor wetland

\subsubsection{Eutrophication control by the Iranian Department of Environment}

Eutrophication is inherently a natural process that may take thousands of years to occur, but human intervention can accelerate it, in which case it is called human-induced eutrophication, which is one of the problems and threats to water bodies. Stopping natural eutrophication is an arduous and almost impossible task, while the human-induced type can be controlled with appropriate measures to limit nutrient-producing resources. The aging of a lake due to eutrophication occurs with warmer and shallower water and eventually turns into a bog or swamp.

The Iranian Department of Environment has recently inaugurated a project to identify the problems associated with Iranian wetlands and accordingly educate local populations to reduce imposed hazards to a possible minimum. Unprecedented algal bloom in the Kani Barazan wetland is one of the main problems caused by its high eutrophication level. As a part of this project, field studies have been conducted to detect and control the 
factors that aggravate the wetland's eutrophication (Mahabad Environmental Protection Organization, 2020). After examining the type of land use in the area, it was found that irrigated agriculture, orchards, dryland agriculture, pastures, saline lands, and wetland are the six main types of land use within the ecological area of the Kani Barazan wetland. According to the results, phosphate and nitrate ions enter the wetland as the main nutritional factors from industrial, rural, and agricultural effluents. Discharging sewage of Qarah Dagh village has been identified as the primary source of entering nutrition into the wetland (Fig. 6). In this regard, training workshops were organized in the surrounding villages to obtain a more comprehensive perspective on the matter to establish a ceiling on human activities that intensify the eutrophication of the wetland.

In this project, the participatory rural appraisal (PRA) survey method was implemented to ask the locals about the wetland's main problems. According to the results, chemical fertilizers, detergents, spraying, manures, and rural sewage were raised as the major problems associated with the wetland's health. Consequently, several solutions were proposed and implemented to resolve this issue, including reducing the usage of chemical fertilizers, separation of sewage from surrounding villages and avoiding its discharge into Mahabad river, treatment of rural domestic wastewater, discharge of rural wastewater into absorbing wells or the use of septic tanks for each neighborhood of the village, sanitary disposal of waste and no dumping into the river, and the use of organic detergents for domestic applications were pointed out to alleviate eutrophication in the wetland. So far, promising results are achieved through continuous monitoring activities and friendly collaboration of local people with authorities.

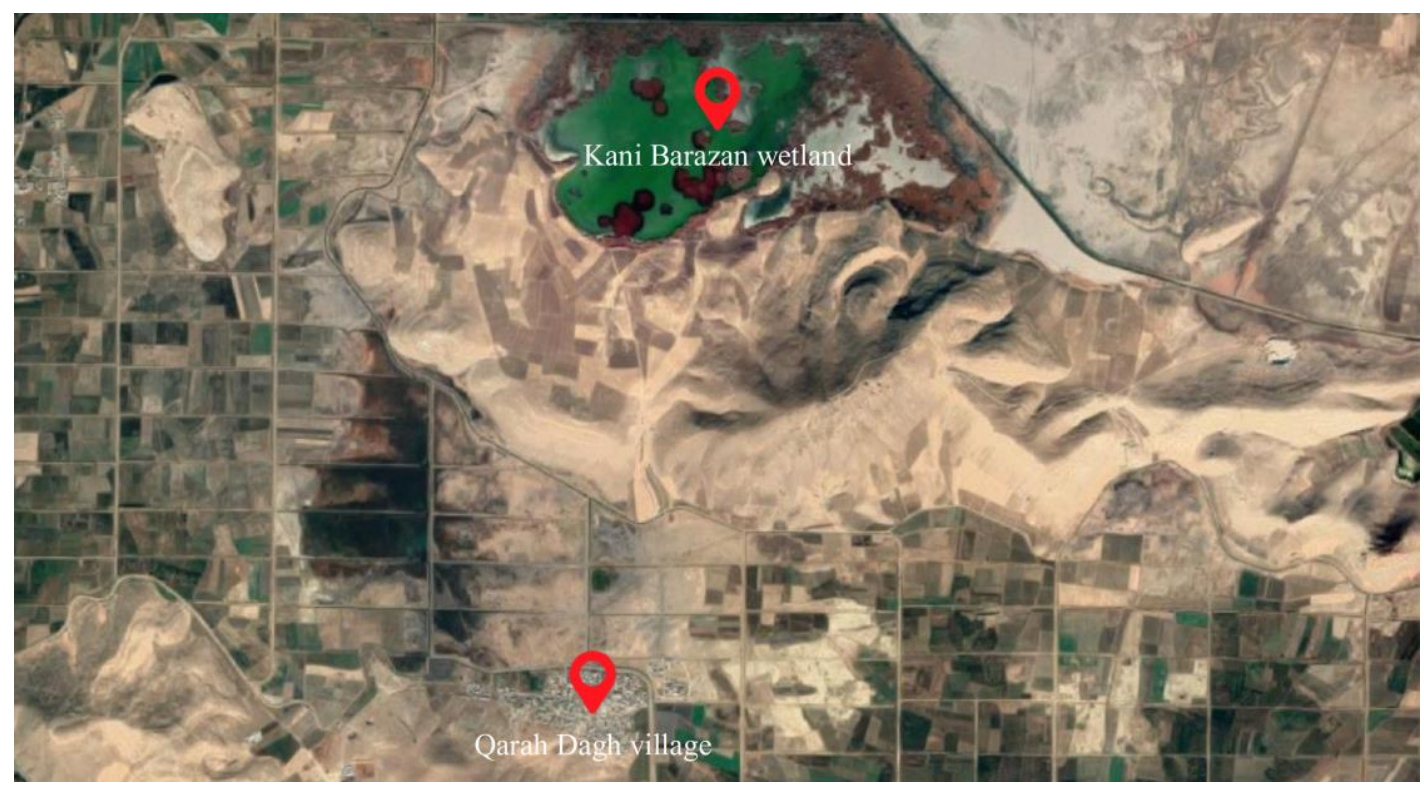

Fig. 6. Relative location of the Kani Barazan wetland and Qarah Dagh village

\subsubsection{Water sampling}

Water samples were collected periodically every three months from April 2019 to April 2020 in the Kani Barazan wetland and from January 2019 to November 2020 in the Choghakhor wetland. Four sampling points (SP) are located in the study areas, with SP3 and SP2 being the online monitoring stations in the Kani Barazan and Choghakhor wetlands, respectively (Fig. 7). The periodic values obtained from these sampling points were averaged to calculate the overall values of the indicators. In line with standard sampling methods, 
nonreactive sampling bottles were rinsed thoroughly two times using the wetland water before sampling. Each sample was analyzed for DO, EC, and $\mathrm{pH}$. All the final samples were collected at the same water level. Immediately after sampling, $\mathrm{pH}$ and EC were measured in situ using a multi-parameter portable meter (TES$1381 \mathrm{~K}$, Taiwan), while DO was measured in the laboratory. The ranges used for scoring these parameters are listed in Table 3.

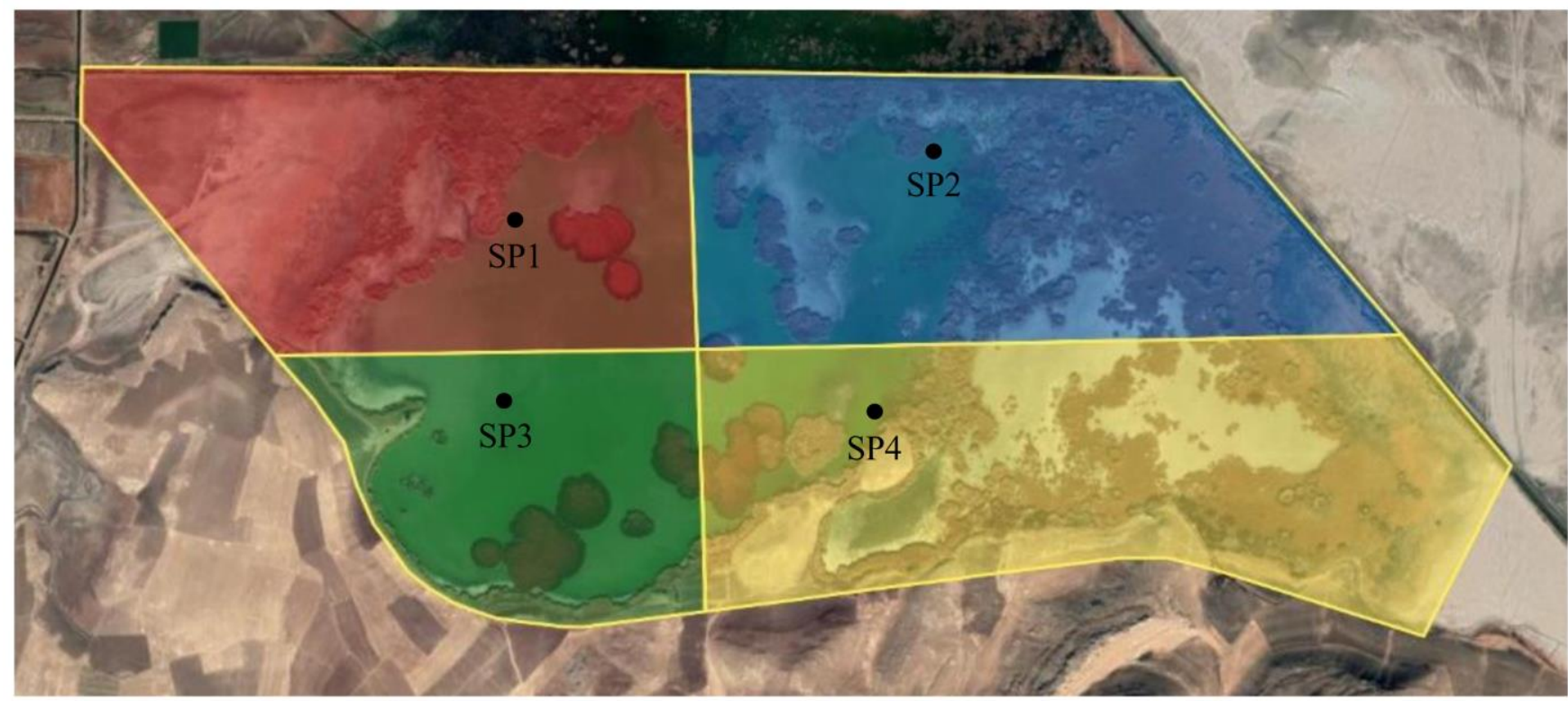

(a) Four parts of the Kani Barazan with water sampling points

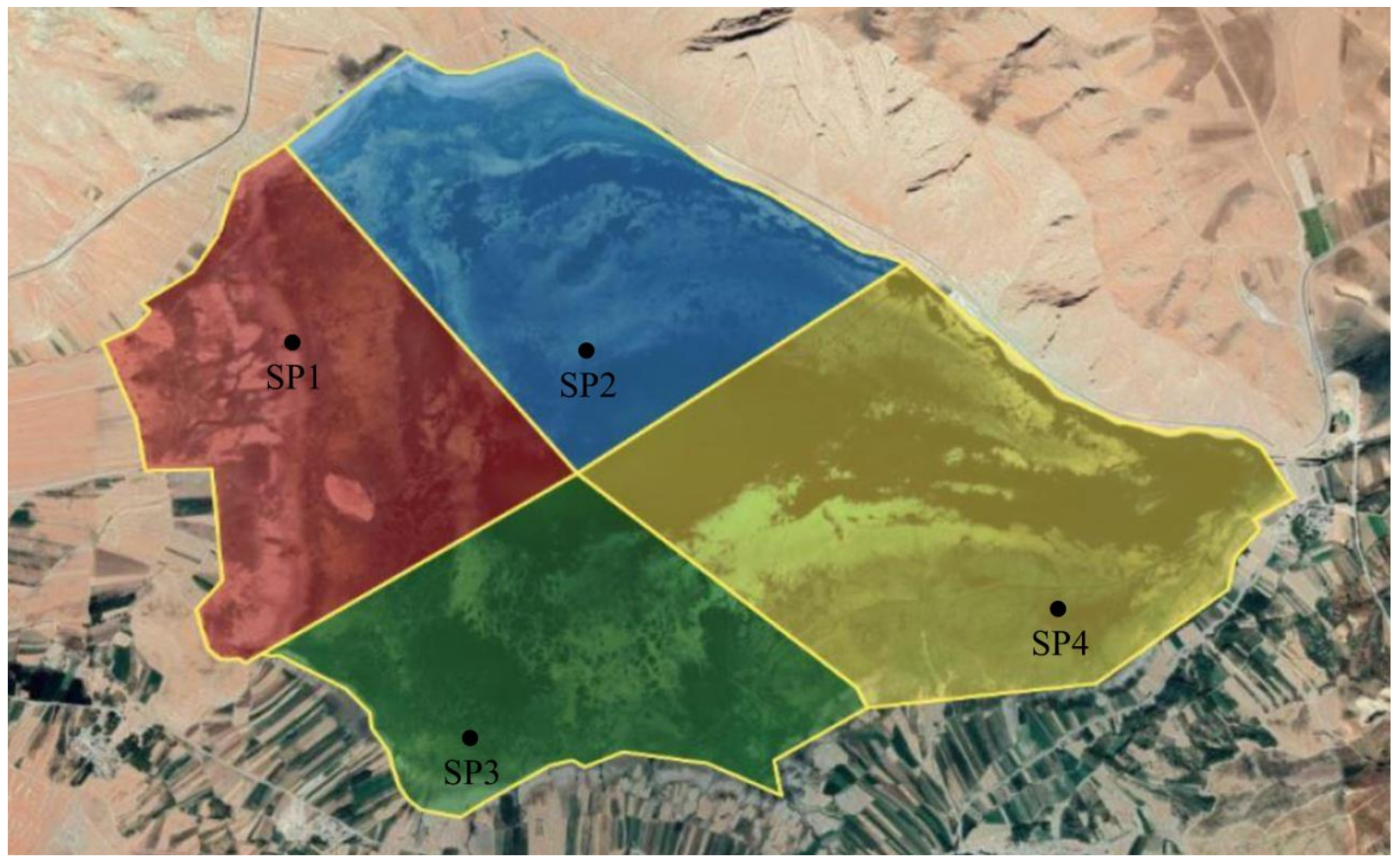

Fig. 7. (b) Four parts of the Choghakhor wetland with water sampling points

\section{Results and discussion}

A fuzzy logic-based approach to assess the wetland health level was developed. The mean values of the selected wetland health indicators were used to test this approach. Weights for wetland health indicators 
calculated with the AHP method are shown in Fig. 8. A questionnaire survey was conducted to collect experts' opinions, including authorities from the Iranian Department of Environment, about the fuzzy rules' weight assignment. The questionnaire consisted of a formally written set of questions and pairwise comparisons of the parameters. Due to topographical, cultural, and political differences between the two selected wetlands and different extents of anthropogenic activities, especially agriculture and livestock grazing in these areas, the use of localized rule weights is necessary to provide a sound evaluation of the ecosystem health status and reflect the local conditions. Therefore, it will be possible to adopt managerial approaches appropriate to each wetland through localized rule weights. In this regard, different rule weights were achieved based on experts' opinions for each study area. However, the physicochemical parameters of water and aquatic vegetation indicators generally played a critical role in the health status of both wetlands.

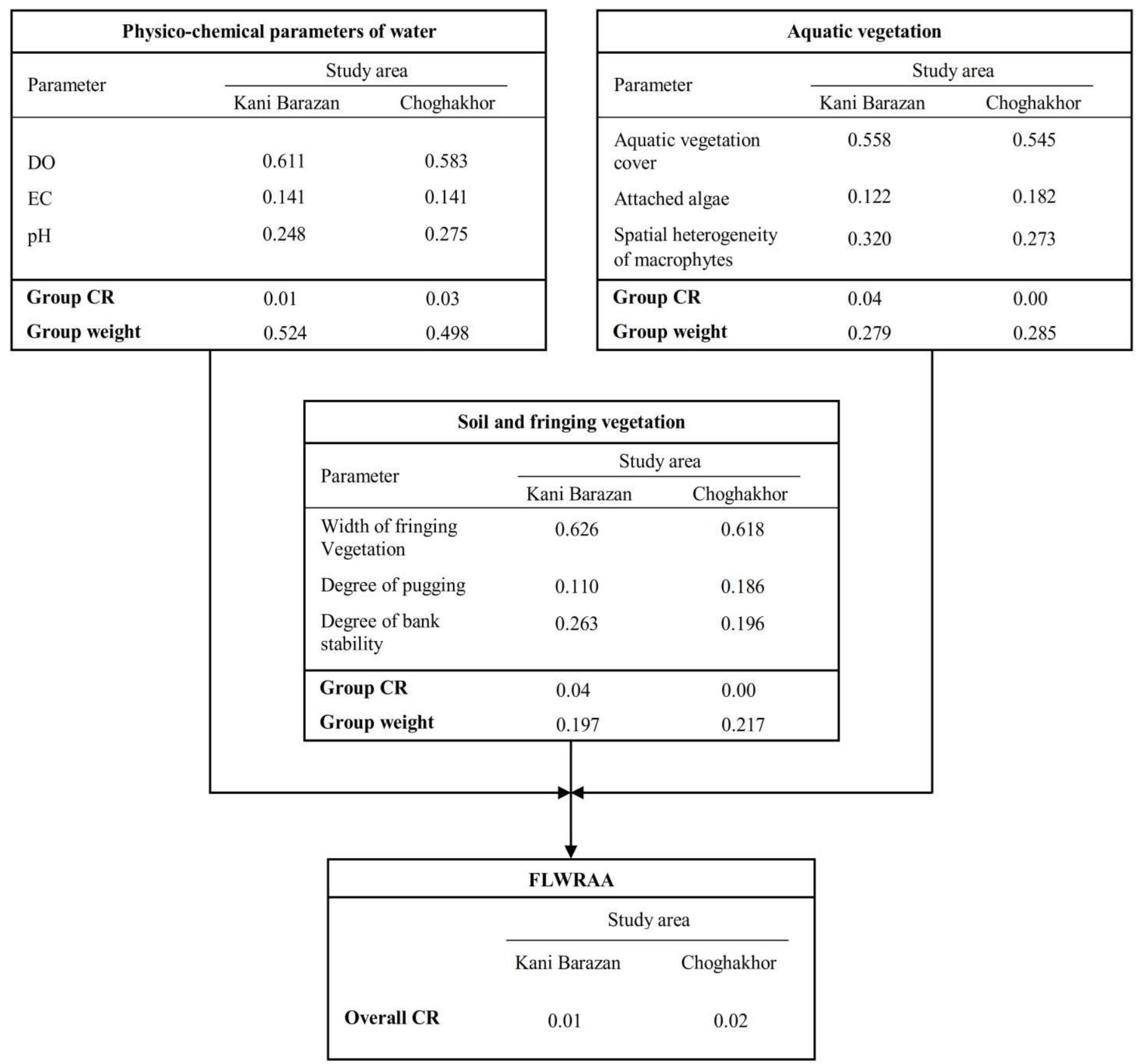

Fig. 8. Optimized weights used in the FLWRAA obtained by the AHP methodology. 


\subsection{Monitoring and interpretation of variations in wetland characteristics}

Among various water quality indicators, the temperature is one of the most instrumental factor influencing nearly all other quality indices to different extents. Apart from its impacts on water quality parameters, physical changes associated with temperature fluctuations in waterbodies also influence the biological activities of organisms present in the aquatic environment, hence, changing oxidation-reduction potential (ORP), metabolic, photosynthetic, and toxicity patterns (Wilde, 2006). Moreover, an increase in water temperature by $10{ }^{\circ} \mathrm{C}$ approximately doubles the physiological function (Di Santo and Bennett, 2011). The higher temperature of wetland water leads to increased respiration rates. Consequently, if extended for a long period, higher oxygen consumption militates against desirable fish life through putrefaction of sludge deposits and facilitating sewage fungus growth. Plants are also other victims of temperature fluctuations. Severe phenomena such as elevated temperatures and droughts can increase the evaporation rate of water, leading to the evolution from aquatic vegetation to semi-arid vegetation and endangering the diversity and biomass of wetland vegetation (Fu et al., 2020). On the other hand, various algae species require different temperature peaks for proper algal photosynthesis (Borlongan et al., 2020). For these reasons, long-term monitoring data on temperature fluctuations can provide useful information about the overall wetland health status and its biological activities.

Exposed to highly variable climatic conditions, the Kani Barazan and Choghakhor wetlands undergo considerable temperature fluctuations throughout the year. During the study period, the mean daily water temperature differences between the coldest and warmest times were respectively $21.87{ }^{\circ} \mathrm{C}$ and $26.08{ }^{\circ} \mathrm{C}$ in 2019 and 2020 in the Choghakhor wetland and $23.6^{\circ} \mathrm{C}$ in the Kani Barazan wetland (Fig. 9).

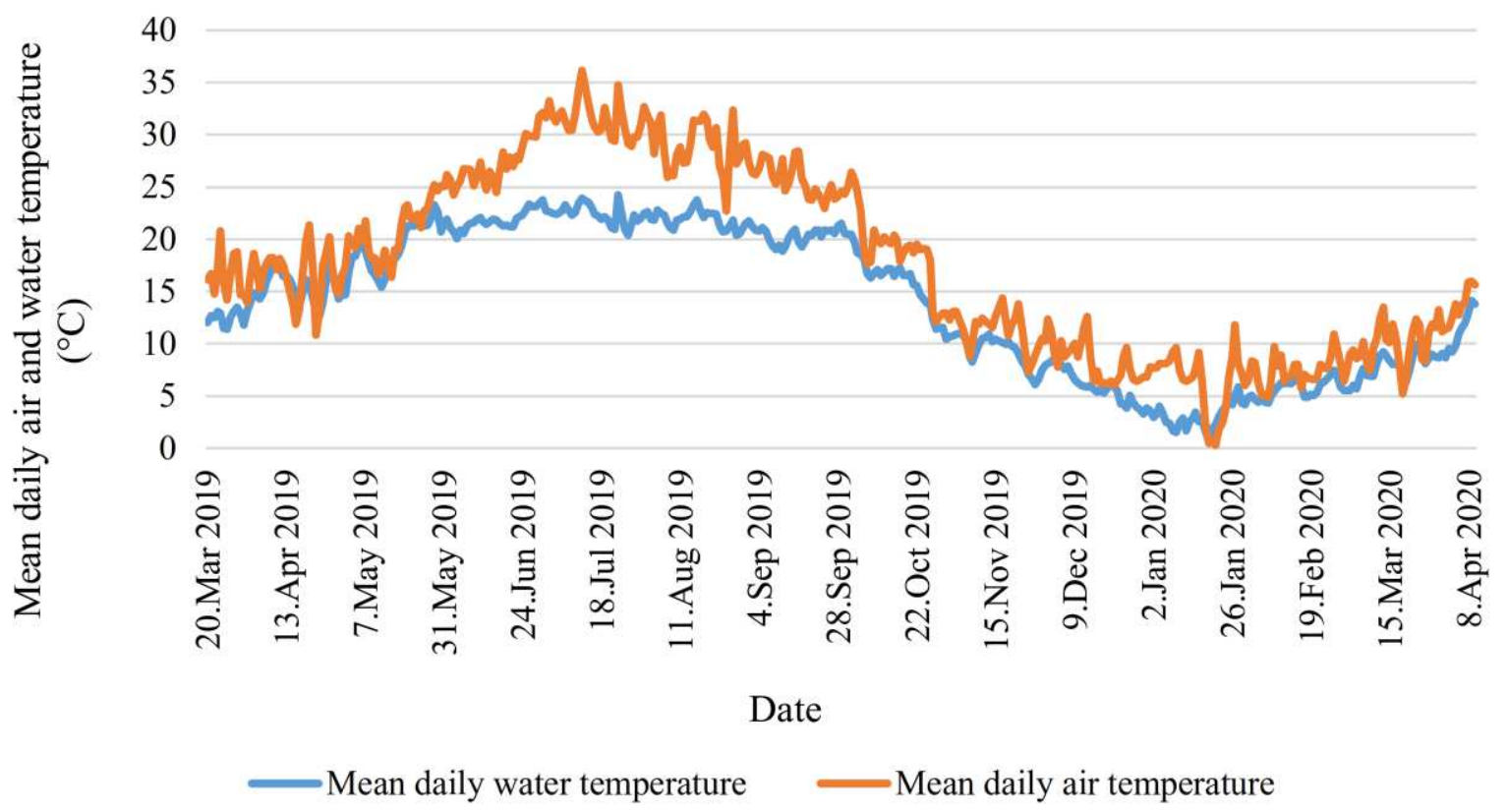

(a) The relationship between mean daily air and water temperature in the Kani Barazan wetland between March 2019 and April 2020. 


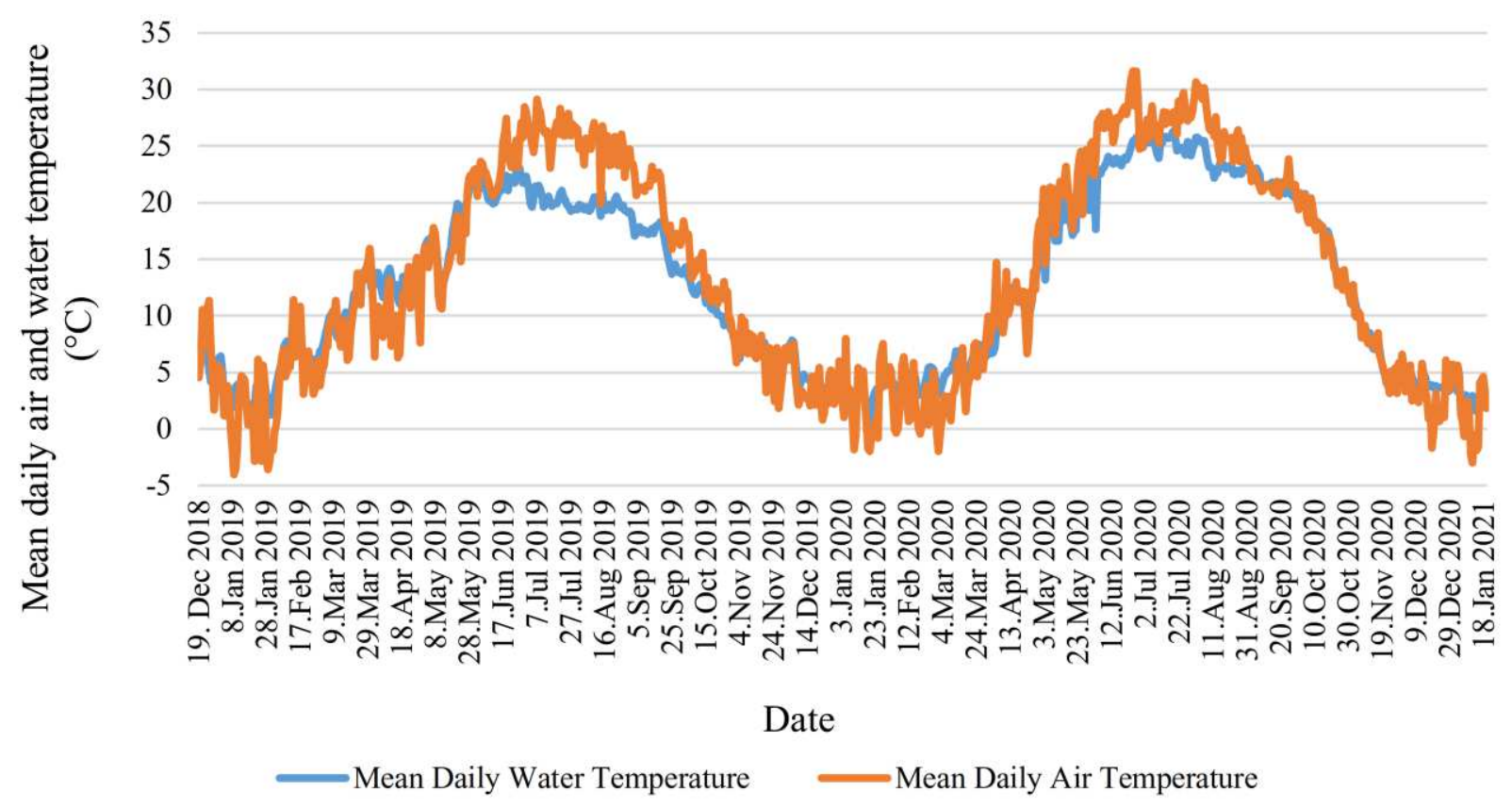

Fig. 9. (b) Relationship between mean daily air and water temperature in the Choghakhor wetland between

December 2018 and January 2021

As two of the most influential physicochemical parameters of water, DO and EC make a significant contribution to the ecological integrity of aquatic ecosystems. In this regard, the relation between water temperature and DO, the most influential parameter in the FLWRAA, along with the impact of EC on DO, was separately tracked by the installed sensors in both wetlands (Fig. 10). Besides the seasonal variations in DO and EC levels caused by natural factors such as climatic processes, inflow, and outflow of the water body, anthropogenic activities can also dramatically influence these parameters, which are the main concern for water resources managers. According to Fig. 10, DO concentrations decrease as water temperature increases, indicating the inverse relationship between DO and temperature. In addition, the seasonal variations in EC levels of the Choghakhor wetland as an indicator of salinity are clearly evident in Fig. 11. On the other hand, there are some abrupt and unusual changes in EC levels of the Kani Barazan wetland that are mainly caused by wastewater discharge and agricultural runoff rich in nutrients and dissolved salts, which in turn facilitate algal growth and promote EC levels. However, this problem is being dealt with by the Iranian Department of Environment as a part of a comprehensive project, which is described in section 3.2, for detecting primary pollution sources to control flows of nutrients and dissolved salts into the wetland. 


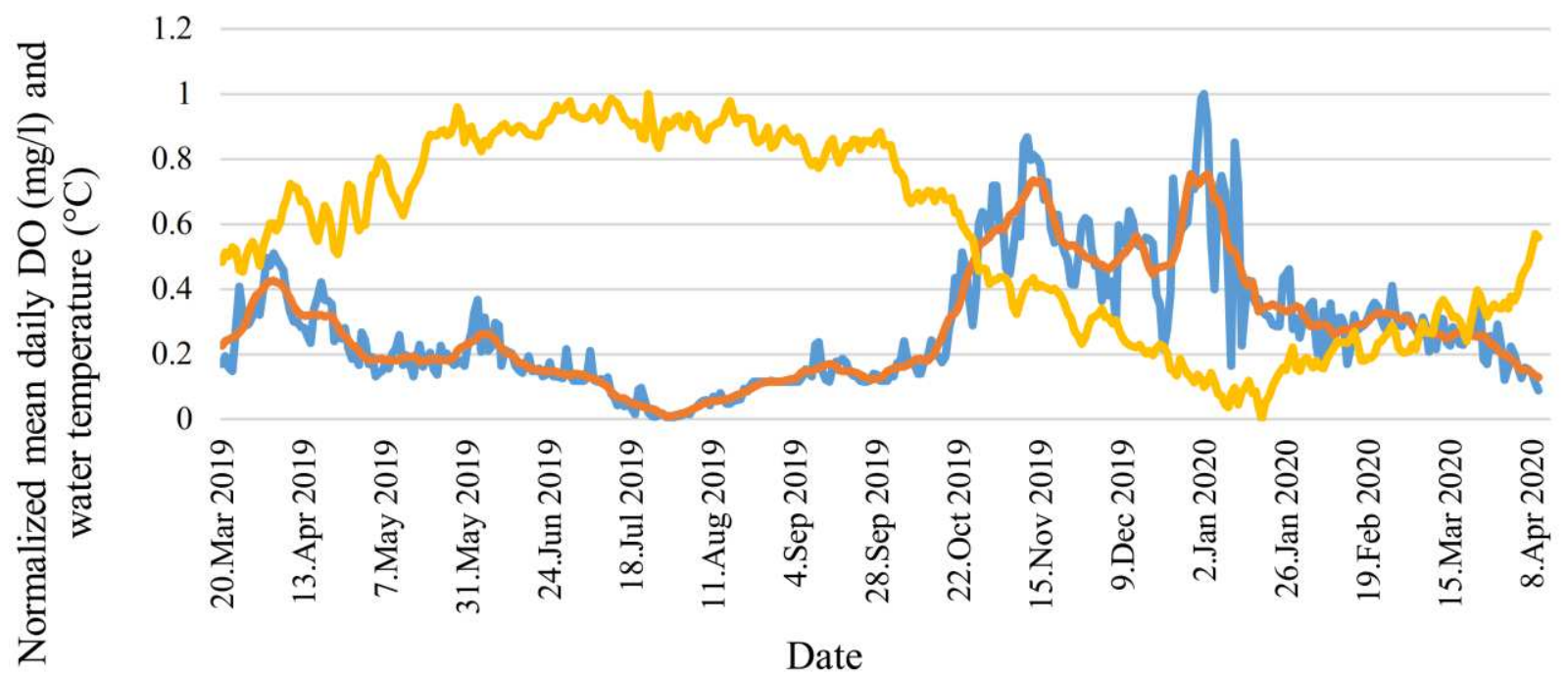

Normalized mean daily DO
Normalized mean daily water temperature

(a) The relationship between mean daily DO and water temperature in the Kani Barazan wetland between March 2019 and April 2020.

1

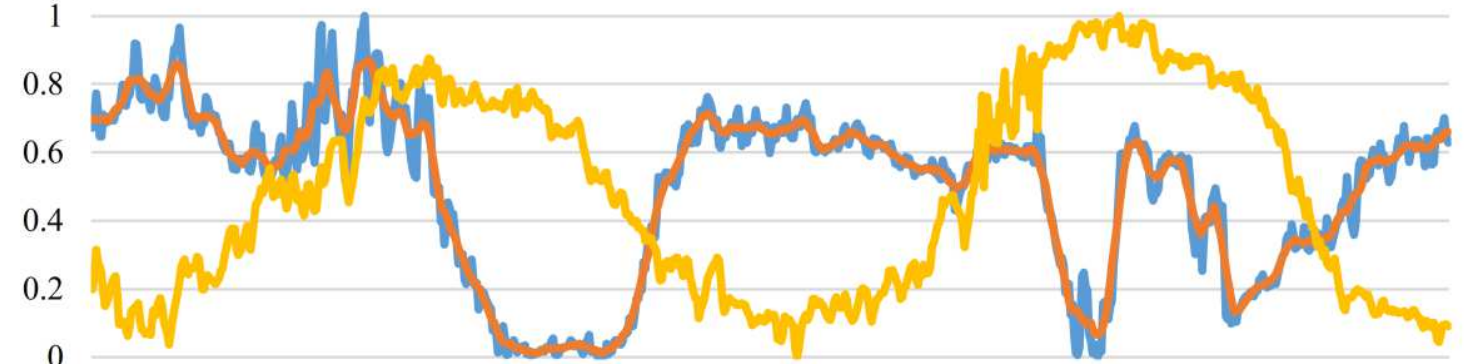

0

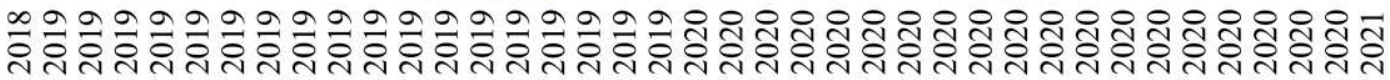
ปี a di

Date

Normalized mean daily DO
Normalized mean daily water temperature

Fig. 10. (b) The relationship between mean daily DO and water temperature in the Choghakhor wetland between December 2018 and January 2021 


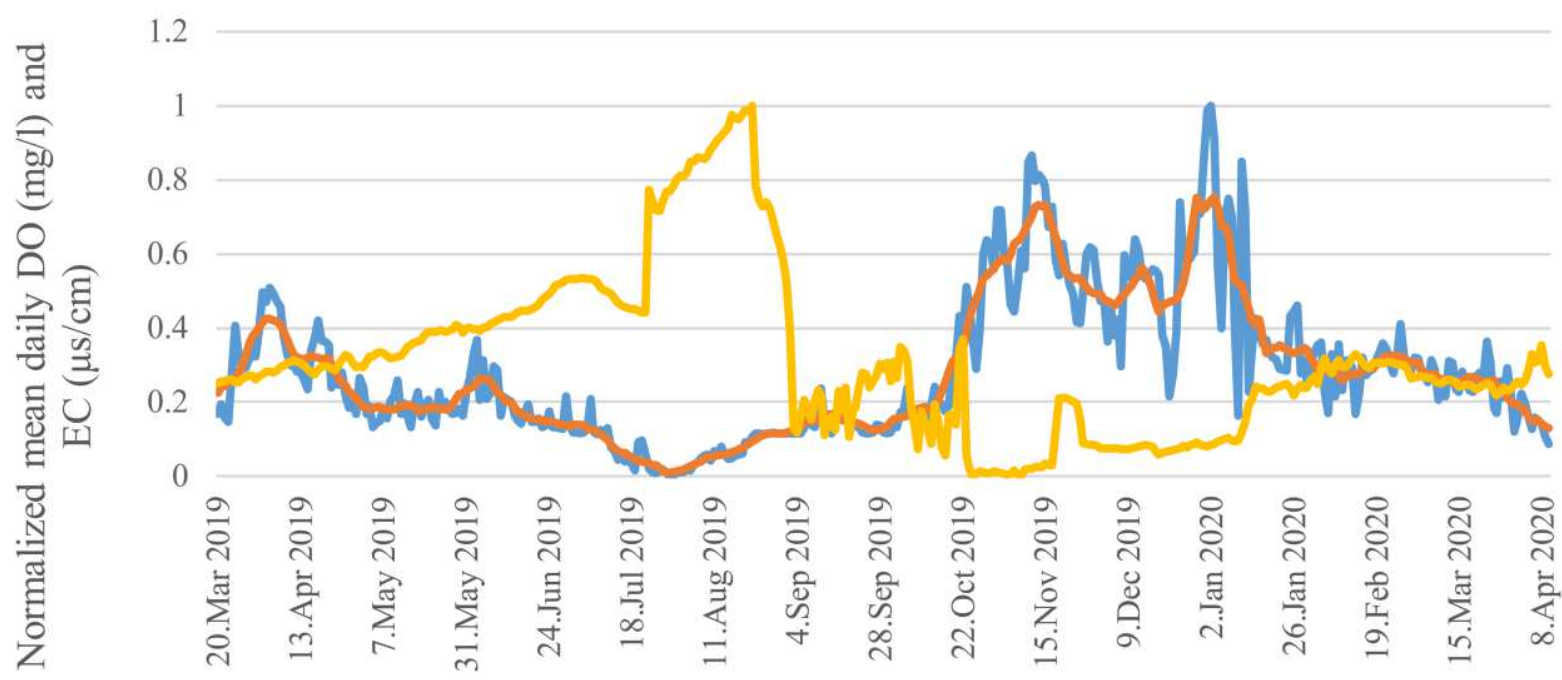

Date

Normalized mean daily DO $\quad$ Smoothed mean daily DO $\quad$ Normalized mean daily EC

(a) The relationship between mean daily DO and EC in the Kani Barazan wetland between March 2019 and April 2020.

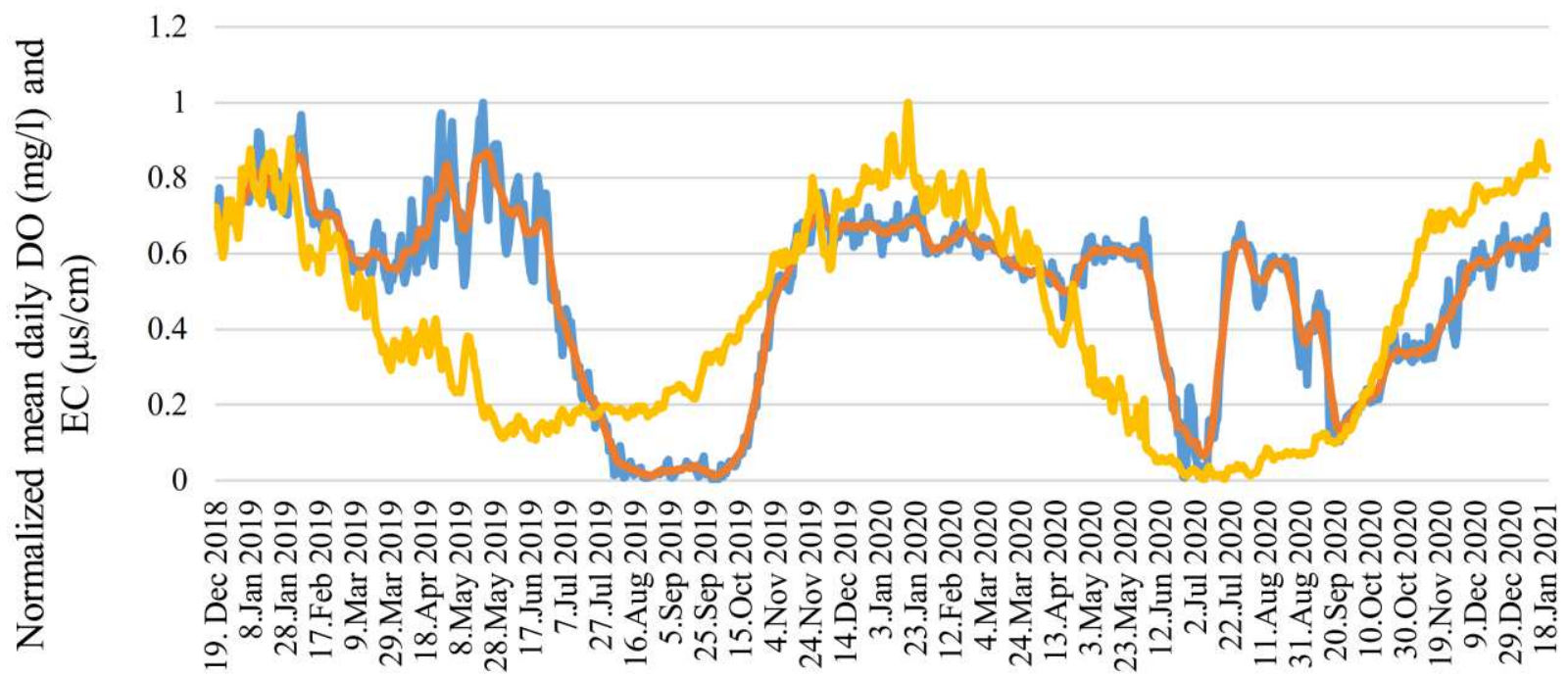

Date

Normalized mean daily DO $\longrightarrow$ Smoothed mean daily DO $\quad$ Normalized mean daily EC

Fig. 11. (b) The relationship between mean daily DO and EC in the Choghakhor wetland between December 2018 and January 2021.

Part 3 of the Kani Barazan wetland was selected to explore short-term temporal variations in this part's health level based on the highest and lowest DO and EC levels via the FLWRAA. The reason for selecting this part was that it is the deepest part of the wetland in which water is always present, and the data on physicochemical parameters of water is recorded every thirty minutes in this part via the online monitoring station, making it possible to track abrupt and short-term changes in water quality parameters. However, the whole wetland's health level was determined using the data collected from all four parts. The mean daily DO and EC values between March 2019 and April 2020 were obtained by averaging the online monitoring station's time-series 
381

382

383

Table 7. Values of wetland health indicators for part 3 of the Kani Barazan wetland

\begin{tabular}{lccccc}
\hline \multirow{2}{*}{ Indicator } & \multirow{2}{*}{ Unit } & \multicolumn{5}{c}{ Date } \\
\cline { 3 - 6 } & & 2-Jan-20 & 30-Jul-19 & 22-Aug-2019 & 25-Oct-19 \\
\hline DO & $(\mathrm{mg} / \mathrm{l})$ & 28.31 & 0.87 & 3.79 & 10.98 \\
$\mathrm{EC}$ & $(\mu \mathrm{s} / \mathrm{cm})$ & 889.70 & 7246.21 & 9264.95 & 121.75 \\
$\mathrm{pH}$ & & 8.61 & 8.78 & 8.78 & 8.32 \\
Aquatic vegetation cover & $(\%)$ & 30 & 35 & 35 & 35 \\
Attached Algae & $\left(\mathrm{cm}^{2}\right)$ & 2200 & 4800 & 4800 & 2000 \\
$\begin{array}{l}\text { Spatial heterogeneity of } \\
\text { macrophytes }\end{array}$ & $(\#)$ & 5 & 5 & 5 & 5 \\
Width of fringing vegetation & $(\mathrm{m})$ & 18 & & & 22 \\
Degree of bank stability & & Moderately high & Moderately high & Moderately high & Moderately high \\
Degree of pugging & $\left(\# / \mathrm{m}^{2}\right)$ & 9 & 11 & 11 & 10 \\
$\begin{array}{l}\text { Closest periodic data } \\
\text { collection date }\end{array}$ & & 16-Jan-20 & 16-Jul-19 & 16-Jul-19 & $16-$ Oct-19 \\
\hline
\end{tabular}

It should be noted that the non-time series data $(\mathrm{pH}$, aquatic vegetation, and soil and fringing vegetation) used in the assessment of WHL based on extreme values of DO and EC were acquired from the closest assessment and data collection period that was carried out with a three-month interval. A comparison between water temperature and WHL results for part 3 based on the mentioned extreme values is shown in Fig. 12.

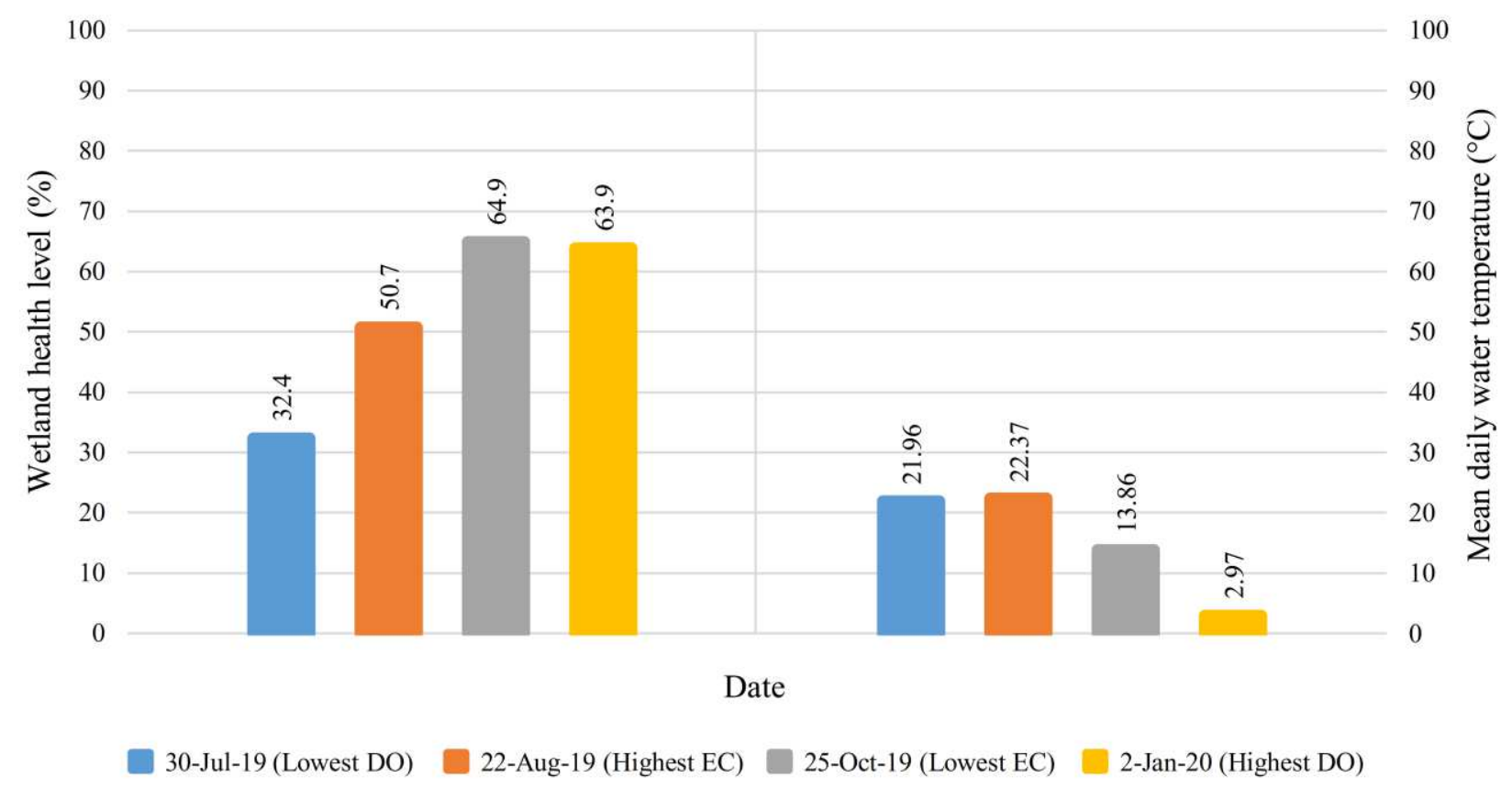

Fig. 12. A comparison between wetland health levels (part 3) based on DO and EC extreme values and mean daily water temperature. 
The wetland health level is in an undesirable state in July, in which the basic ecosystem functions can be disrupted if such a condition persists. On August 22, despite the continuous increase of EC levels, the wetland partially recovers from this state as DO levels increase. As it is evident, a dramatic increase in the EC level followed by a decreased DO level can significantly affect wetland health, even though the values of other indicators, except for $\mathrm{pH}$, remain above moderate levels. The DO levels remain under an acceptable hypoxia threshold (5-6 mg/l) (Farrell and Richards, 2009) for freshwater environments from late June to September. This phenomenon can be traced back to a sudden increase in EC levels caused by an excessive supply of nutrients, especially nitrogen and phosphorus, from agricultural runoff and elevated temperatures. High availability of nutrients (eutrophication) stimulates the excessive growth of algae, causing dissolved oxygen depletion. Such a long-lasting eutrophic state, followed by hypoxia (low dissolved oxygen levels), can cause irreversible damage to the wetland's sensitive species. In the following months, as DO levels increase and EC levels drop remarkably, the conditions become more favorable for further improvement of the wetland health. As it is evident, physicochemical parameters of water play a more crucial role in the overall health status of the wetland than other groups of parameters. Although the wetland experiences severe short-term conditions, its overall function and biological integrity will remain undisturbed as long as such conditions do not persist for an extended time. Physicochemical parameters are highly susceptible to human disturbance and can undergo dramatic changes to a point where the wetland's overall health status can be impacted; therefore, an optimized approach that incorporates weighted parameters and is sensitive to local conditions and the human activities that take place in the area is essential for providing more realistic wetland health status results.

\subsection{Evaluation of the wetland health level via FLWRAA}

Risk assessment is an integral part of sustainable wetland management, where the ecosystem's health and wise exploitation are ensured. In this regard, the health status of the Kani Barazan and Choghakhor wetlands, as two of the most important Iranian Ramsar sites, were assessed with both the proposed FLWRAA and the traditional ESCOM's WCRAI to ensure an accurate and reliable risk assessment of the ecosystems and evaluate the applicability of the proposed approach. Table 8 represents the results of field measurements for four parts of the study areas. The measurements were carried out periodically every three months from April 2019 to April 2020 in the Kani Barazan wetland and from January 2019 to November 2020 in the Choghakhor wetland

Table 8. Mean values of the wetland health indicators

The Kani Barazan wetland

\begin{tabular}{llcccc}
\hline \multirow{2}{*}{ Indicator } & \multirow{2}{*}{ Unit } & \multicolumn{4}{c}{ Wetland part } \\
\cline { 3 - 6 } & & Part 1 & Part 2 & Part 3 & Part 4 \\
\hline DO & $(\mathrm{mg} / \mathrm{l})$ & 6.82 & 7.22 & 8.42 & 7.14 \\
$\mathrm{EC}$ & $(\mu \mathrm{s} / \mathrm{cm})$ & 3856 & 4466 & 3122 & 4258 \\
$\mathrm{pH}$ & & 8.2 & 8.51 & 8.67 & 8.75 \\
Aquatic vegetation cover & $(\%)$ & 20 & 30 & 35 & 45
\end{tabular}


Attached Algae $\left(\mathrm{cm}^{2}\right)$

Spatial heterogeneity of macrophytes (\#)

Width of fringing vegetation

Degree of bank stability

Degree of pugging (m)

$\left(\# / \mathrm{m}^{2}\right)$
2300

5

23

High
3600

6

32

High
3200

5

21

Moderately high Moderately high 11
3000

6

38

14

The Choghakhor wetland (2019)

\begin{tabular}{lccccc}
\hline \multirow{2}{*}{ Indicator } & \multirow{2}{*}{ Unit } & \multicolumn{4}{c}{ Wetland part } \\
\cline { 3 - 6 } & & Part 1 & Part 2 & Part 3 & Part 4 \\
\hline DO & $(\mathrm{mg} / \mathrm{l})$ & 6.28 & 6.59 & 5.26 & 5.64 \\
EC & $(\mu \mathrm{s} / \mathrm{cm})$ & 340.69 & 328.98 & 510.17 & 507.42 \\
pH & & 9.65 & 9.73 & 9.86 & 9.92 \\
Aquatic vegetation cover & $(\%)$ & 25 & 20 & 30 & 30 \\
Attached Algae & $\left(\mathrm{cm}^{2}\right)$ & 3800 & 3700 & 4200 & 4000 \\
Spatial heterogeneity of macrophytes & $(\#)$ & 3 & 2 & 3 & 2 \\
Width of fringing vegetation & $(\mathrm{m})$ & 2.5 & 1.5 & 2 & 1.5 \\
Degree of bank stability & & Medium & Medium & Moderately high & Moderately high \\
Degree of pugging & $\left(\# / \mathrm{m}^{2}\right)$ & 11 & 12 & 8 & 10
\end{tabular}

The Choghakhor wetland (2020)

\begin{tabular}{lccccc}
\hline \multirow{2}{*}{ Indicator } & Unit & \multicolumn{4}{c}{ Wetland part } \\
\cline { 3 - 6 } & & Part 1 & Part 2 & Part 3 & Part 4 \\
\hline DO & $(\mathrm{mg} / \mathrm{l})$ & 4.62 & 5.18 & 4.34 & 4.23 \\
EC & $(\mu \mathrm{s} / \mathrm{cm})$ & 351.72 & 330.16 & 532.26 & 546.34 \\
pH & & 9.13 & 9.04 & 9.21 & 9.37 \\
Aquatic vegetation cover & $(\%)$ & 20 & 20 & 25 & 25 \\
Attached Algae & $\left(\mathrm{cm}^{2}\right)$ & 4000 & 4000 & 4500 & 4700 \\
Spatial heterogeneity of macrophytes & $(\#)$ & 3 & 2 & 3 & 2 \\
Width of fringing vegetation & $(\mathrm{m})$ & 2 & 2 & 1.5 & 2 \\
Degree of bank stability & & Medium & Medium & Moderately high & Medium \\
Degree of pugging & $\left(\# / \mathrm{m}^{2}\right)$ & 13 & 12 & 8 & 10 \\
\hline
\end{tabular}

417 For the Kani Barazan wetland health level, the overall output scores of $58.62 \%$ and $63.19 \%$ were respectively obtained from the FLWRAA and the traditional framework. The health assessment of the Choghakhor wetland was conducted between 2019 and 2020. The results obtained from both frameworks confirmed a decline in the wetland health level in 2020 compared to 2019. The FLWRAA generated overall scores of $48.75 \%$ and 42.92\% for the Choghakhor wetland health level for 2019 and 2020, respectively. On the other hand, the overall scores of $51.38 \%$ and $46.52 \%$ were respectively achieved for 2019 and 2020 using the traditional framework. Although the traditional framework generated higher scores than FLWRAA, the results of both frameworks were consistent. The output scores were categorized using an A-F ecological scale to determine the wetland health status (Table 9). 
Table 9. Description of the A-F ecological categories (Oberholster et al., 2014)

\begin{tabular}{|c|c|c|}
\hline Ecological category & Score in percentage $(\%)$ & Description \\
\hline A & $90-100$ & Unmodified (natural) \\
\hline $\mathrm{B}$ & $80-90$ & $\begin{array}{l}\text { Mostly natural with few modifications. A few small-scale natural } \\
\text { habitats and biota changes may have occurred, but the ecosystem } \\
\text { functions are essentially unchanged. }\end{array}$ \\
\hline $\mathrm{C}$ & $60-80$ & $\begin{array}{l}\text { Moderately modified. Changes in and loss of natural habitat and } \\
\text { biota have occurred, but the basic ecosystem functions are still } \\
\text { predominantly unchanged. }\end{array}$ \\
\hline D & $40-60$ & $\begin{array}{l}\text { Largely modified. A massive loss of natural habitat, biota, and } \\
\text { basic ecosystem function has occurred. }\end{array}$ \\
\hline $\mathrm{E}$ & $20-40$ & $\begin{array}{l}\text { Seriously modified. The loss of natural habitat, biota, and basic } \\
\text { ecosystem functions is extensive. }\end{array}$ \\
\hline $\mathrm{F}$ & $0-20$ & $\begin{array}{l}\text { Critically modified. Modifications have reached a critical level, } \\
\text { and the system has been entirely modified with an almost } \\
\text { complete loss of natural habitat and biota. }\end{array}$ \\
\hline
\end{tabular}

Based on this scale, the output score of the FLWRAA for the Kani Barazan wetland can be categorized as "D," while the output score of the traditional framework falls into the category of "C." Similarly, scores obtained from the FLWRAA and the traditional framework for the Choghakhor wetland can be categorized as "D," albeit a decline of about 5\% is evident in the scores of both frameworks for 2020 in comparison to that of 2019. In general, the FLWRAA yielded lower scores for both study areas. For the Kani Barazan wetland, parts 1, 4, and the wetland's overall health status fell into lower categories, indicating a more disturbed ecosystem. A similar trend is also evident in the Choghakhor wetland's scores, even though they fell into the same ecological categories when using the A-F scale. A comparison between the results of the proposed FLWRAA and the ESCOM's WCRAI is depicted in Fig. 13. The difference in results stems from the fact that the traditional framework employs equally weighted indicators in which parameters with lower importance, such as the degree of pugging, dramatically affect the output score and lead to unrealistic results. On the other hand, the role of critical parameters such as DO and aquatic vegetation cover was underestimated. According to the achieved results, more deliberate and conservative managerial strategies are required to prevent the further degradation of both wetlands and alleviate their damaged parts. 


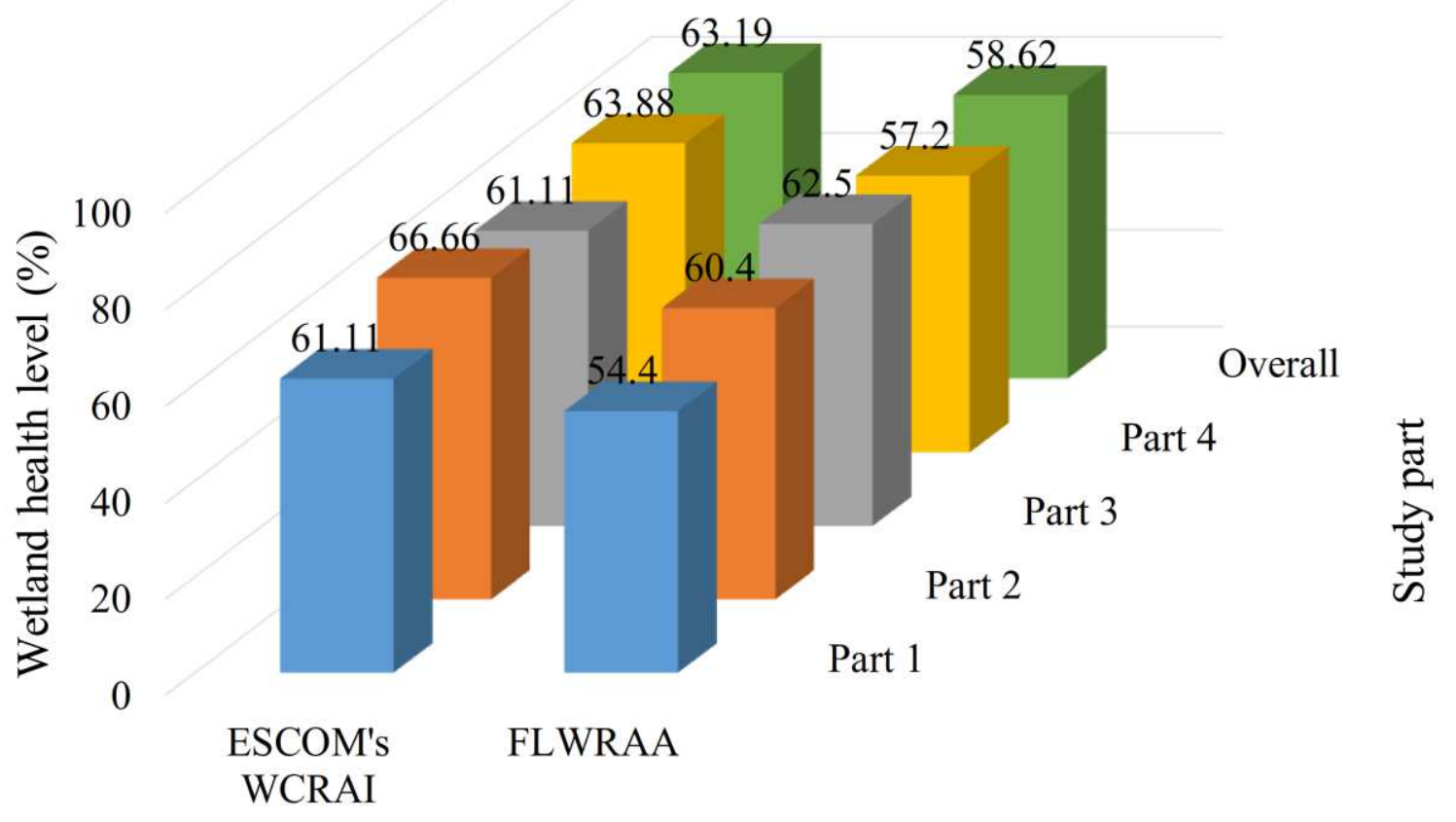

Risk assessment framework

(a) Results for health level of the Kani Barazan wetland

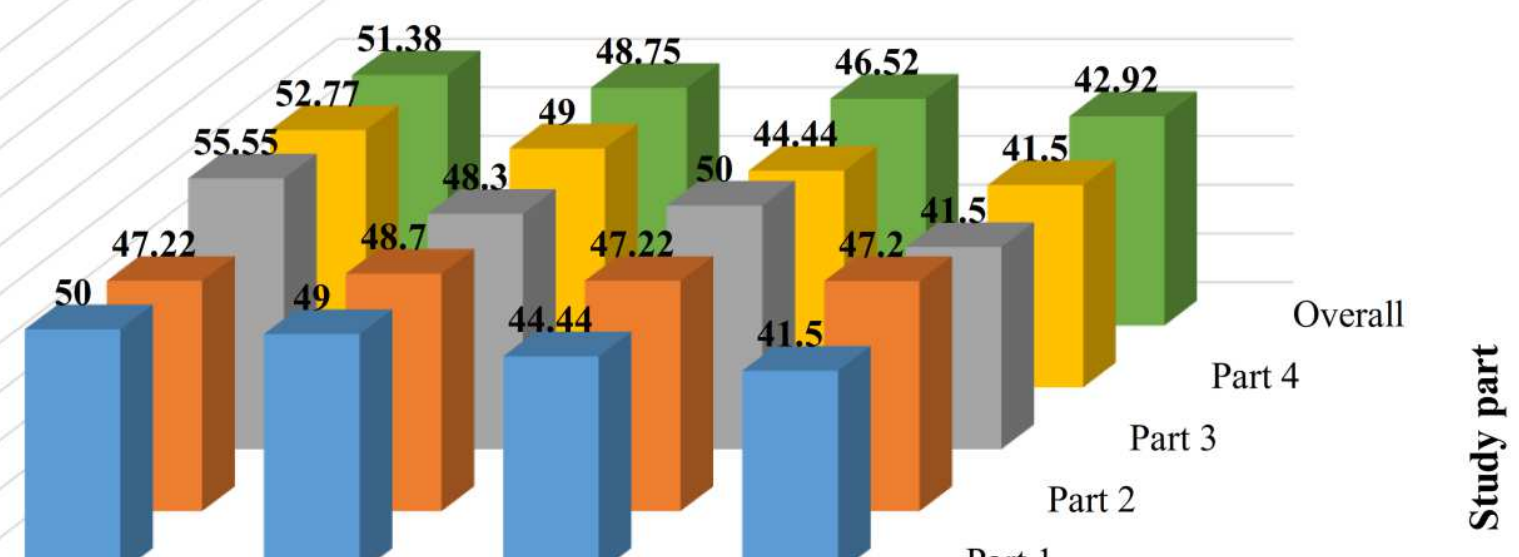
ESCOM's
WCRAI (2019)
FLWRAA
$(2019$
ESCOM's
FLWRAA
(2020)

Risk assessment framework

Fig. 13. (b) Results for health level of the Choghakhor wetland in 2019 and 2020

\section{Conclusions}

This paper investigates a new fuzzy logic-based wetland risk assessment approach (FLWRAA) to improve the traditional ESCOM's wetland classification and risk assessment index (WCRAI), using automatically and 
manually collected data. For this purpose, the relative importance of the wetland health indicators involved in the fuzzy inference system was determined using the AHP weighting methodology. The Kani Barazan and Choghakhor wetlands were selected as hotspot sites to demonstrate the applicability of the proposed approach for managing Iran's wetland protected areas. The following conclusions can be drawn: The sensitivity analysis process emphasizes that the untreated wastewater and agricultural runoff that contain high amounts of nutrients and dissolved salts considerably influence DO levels of the Kani Barazan wetland by manifesting their effects on facilitating algal growth and promoting EC levels. By averaging time-series data obtained from the Kani Barazan wetland's online monitoring station, it was observed that the lowest $(0.87$ $\mathrm{mg} / \mathrm{l})$ and highest (28.31 mg/l) mean daily DO levels respectively appeared on July 30, 2019, and January 2, 2020. Also, the highest $(9264.95 \mu \mathrm{S} / \mathrm{cm})$ and lowest $(121.75 \mu \mathrm{S} / \mathrm{cm})$ mean daily EC levels were recorded on August 22, 2019, and October 25, 2019, respectively. However, according to the comprehensive project conducted by the Iranian Department of Environment for controlling eutrophication in Iranian wetlands, including the considered wetlands of this study, promising improvements were observed in the overall wetland health level. In this regard, managing the agricultural runoff and preventing the discharge of untreated wastewater to the wetlands can significantly contribute to the wetland health status and pave the way for the success of the Iranian Department of Environment in controlling the eutrophication in Iranian wetlands.

The health level of the Kani Barazan and Choghakhor wetlands were assessed with both the FLWRAA and the ESCOM's WCRAI. For the Kani Barazan wetland, an overall output score of $63.19 \%$ (C) was obtained from the traditional index. In turn, the overall score of $58.62 \%$ (D) was achieved using the FLWRAA, indicating a more disturbed wetland that falls into a lower ecological category compared to the result yielded by the traditional index. On the other hand, for the Choghakhor wetland, the overall scores of $51.38 \%$ (D) and 46.52\% (D) were achieved using the ESCOM's WCRAI for 2019 and 2020, respectively. In turn, the FLWRAA yielded $48.75 \%$ (D) and 42.92\% (D), respectively, for 2019 and 2020. Although the scores generated by the FLWRAA for the Choghakhor wetland were lower than that of the ESCOM's WCRAI, they all were categorized as "D" based on the A-F ecological category. The differences in both wetlands' scores stem from the fact that the traditional framework employs unweighted indicators, which in turn, parameters with lower importance, such as the degree of pugging, significantly affect the output score, and critical parameters such as DO is underestimated.

This study highlights the importance of continuous wetland health monitoring and early warning systems. Properly utilizing the daily time-series data recorded by the online monitoring stations' sensors can secure the wetland's ecological integrity against anthropogenic and natural hazards. Moreover, the proposed AHP-FIS based wetland risk assessment approach can yield more realistic results due to using exclusively weighted parameters for the wetland that are generated based on experts' opinions and knowledge to deal with the inefficiencies associated with the traditional approach. While it does not necessarily lead to different categories of aggregated scores, as seen for the second case study (the Choghakhor wetland), the observed differences in health level categories of the first case study emphasize the importance of using the AHP-FIS 
method to improve the traditional approach. The proposed method shows a suitable environmental application of FIS integrating various wetland health indicators. A combination of FIS and AHP methodologies vividly improved the efficiency of the traditional ESCOM's WCRAI. The flexibility of fuzzy logic in developing classification models based on natural language, coupled with the AHP methodology's ability to arrange and analyze complex decision-making problems based on experts' opinions, provides a realistic and reliable picture of the wetland health status.

\section{Declarations}

\section{Ethics approval}

This article does not violate rights of any kind, as it does not contain any studies with human participants performed by any of the authors. This article does not contain any studies with animals performed by any of the authors. Informed consent was obtained from all individual participants included in the study.

\section{$\underline{\text { Acknowledgments }}$}

The authors graciously acknowledge the "Conservation of Iranian Wetlands Project" office for assistance in data acquisition and partially supported by the Iranian Department of Environment under the project No. t/9863.

\section{Authors' contributions}

SSH contributed to developing the overall methodology, goals of the study, performed the software-based parts and wrote the original draft. AM supervised and administrated the project and designed the overall scheme of the research, conceptualization, and final editing. AMR took his part in conceptualization and writing the original draft.

\section{Funding}

Not applicable. This study was not funded by any company or other references.

\section{Conflict of Interest Statement}

The authors have all agreed to the submission of the current manuscript.

The authors declare that they have no known competing financial interests or personal relationships that could have appeared to influence the work reported in this paper.

\section{Consent to participate}

Not applicable.

\section{Consent for publication}

Not applicable.

\section{Availability of data and material}

512 Not applicable.

\section{Code availability}

Not applicable. 


\section{References}

Abdel-Basset, M., Mohamed, M., 2018. The role of single valued neutrosophic sets and rough sets in smart city: imperfect and incomplete information systems. Measurement 124, 47-55.

A1 Mamun, M.A., Howladar, M.F., Sohail, M.A., 2019. Assessment of surface water quality using Fuzzy Analytic Hierarchy Process (FAHP): A case study of Piyain River's sand and gravel quarry mining area in Jaflong, Sylhet. Groundwater for Sustainable Development 9, 100208.

Andrecut, M., 2014. Decision Making via AHP. Retrieved from http://arxiv.org/abs/1402.1976.

Ávila-Flores, G., Juárez-Mancilla, J., Hinojosa-Arango, G., Cruz-Chávez, P., López-Vivas, J.M., ArizpeCovarrubias, O., 2020. A practical index to estimate mangrove conservation status: The forests from La Paz Bay, Mexico as a case study. Sustainability 12, 858 .

Bilgiç, T., TürkŞen, I.B., 2000. Measurement of membership functions: theoretical and empirical work, in: Fundamentals of Fuzzy Sets. Springer, pp. 195-227.

Borlongan, I.A., Suzuki, S., Nishihara, G.N., Kozono, J., Terada, R., 2020. Effects of light quality and temperature on the photosynthesis and pigment content of a subtidal edible red alga Meristotheca papulosa (Solieriaceae, Gigartinales) from Japan. Journal of Applied Phycology 1-12.

de Oliveira, M.D., de Rezende, O.L.T., de Fonseca, J.F.R., Libânio, M., 2019. Evaluating the surface Water quality index fuzzy and its influence on water treatment. Journal of Water Process Engineering 32, 100890.

Di Santo, V., Bennett, W.A., 2011. Effect of rapid temperature change on resting routine metabolic rates of two benthic elasmobranchs. Fish physiology and biochemistry 37, 929-934.

Dutta, P., Ali, T., 2012. Uncertainty modeling in risk analysis: a fuzzy set approach. International Journal of Computer Applications 43, 35-39.

Farrell, A.P., Richards, J.G., 2009. Defining hypoxia: an integrative synthesis of the responses of fish to hypoxia, in: Fish Physiology. Elsevier, pp. 487-503.

Fennessy, M.S., Jacobs, A.D., Kentula, M.E., 2004. Review of rapid methods for assessing wetland condition. EPA/620/R-04/009. US Environmental Protection Agency, Washington, DC.

Fu, J., Liu, J., Wang, X., Zhang, M., Chen, W., Chen, B., 2020. Ecological risk assessment of wetland vegetation under projected climate scenarios in the Sanjiang Plain, China. Journal of Environmental Management 273, 111108.

Gardner, R.C., Finlayson, C., 2018. Global wetland outlook: state of the World's wetlands and their services to people, in: Ramsar Convention Secretariat. Retrieved from https://Papers.Ssrn.Com/Sol3/Papers.Cfm?Abstract_id=3261606.

Ghosh, S., Das, A., 2020. Wetland conversion risk assessment of East Kolkata Wetland: A Ramsar site using random forest and support vector machine model. Journal of Cleaner Production 275, 123475.

Hu, X., Ma, C., Huang, P., Guo, X., 2021. Ecological vulnerability assessment based on AHP-PSR method and analysis of its single parameter sensitivity and spatial autocorrelation for ecological protection - A case of Weifang City, China. Ecological Indicators 125, 107464.

Jianga, W., Lv, J., Wangd, C., Chen, Z., Liu, Y., 2017. Marsh wetland degradation risk assessment and change analysis: A case study in the Zoige Plateau, China. Ecological Indicatorso 82, 316-326.

Komsiyah, S., Desvania, E., 2021. Traffic Lights Analysis and Simulation Using Fuzzy Inference System of Mamdani on Three-Signaled Intersections. Procedia Computer Science 179, 268-280.

Lermontov, A., Yokoyama, L., Lermontov, M., Machado, M.A.S., 2009. River quality analysis using fuzzy water quality index: Ribeira do Iguape river watershed, Brazil. Ecological Indicators 9, 1188-1197.

Mahabad Environmental Protection Organization, 2020. Identifying the current situation, formulating and implementation of an action plan to reduce the eutrophication of the Kani Barazan and Ghori Gol wetlands with the awareness and cooperation of local communities.

Mansouri, B., Majnoni, F., 2014. Comparison of the metal concentrations in organs of two bird species from western of Iran. Bulletin of environmental contamination and toxicology 92, 433-439.

Mao, B., Ao, C., Wang, J., Xu, L., 2019. The importance of loss aversion in public preferences for wetland management policies: evidence from a choice experiment with reference-dependent discrete choice model. Wetlands $1-10$.

Mojtahedi, A., Soori, N., Mohammadian, M., 2020. Energy dissipation evaluation for stepped spillway using a fuzzy inference system. SN Applied Sciences 2, 1466.

Nasseri, H., 2008. Fuzzy numbers: positive and nonnegative, in: International Mathematical Forum. pp. 
$1777-1780$.

Nayak, J.G., Patil, L.G., Patki, V.K., 2020. Development of water quality index for Godavari River (India) based on fuzzy inference system. Groundwater for Sustainable Development 10, 100350.

Oberholster, P.J., Blaise, C., Botha, A.-M., 2010. Phytobenthos and phytoplankton community changes upon exposure to a sunflower oil spill in a South African protected freshwater wetland. Ecotoxicology 19, $1426-1439$.

Oberholster, P.J., McMillan, P., Durgapersad, K., Botha, A.M., De Klerk, A.R., 2014. The development of a Wetland Classification and Risk Assessment Index (WCRAI) for non-wetland specialists for the management of natural freshwater wetland ecosystems. Water, Air, and Soil Pollution 225, 1-15.

Ocampo-Duque, W., Ferre-Huguet, N., Domingo, J.L., Schuhmacher, M., 2006. Assessing water quality in rivers with fuzzy inference systems: A case study. Environment International 32, 733-742.

Ocampo-Duque, W., Osorio, C., Piamba, C., Schuhmacher, M., Domingo, J.L., 2013. Water quality analysis in rivers with non-parametric probability distributions and fuzzy inference systems: Application to the Cauca River, Colombia. Environment international 52, 17-28.

Oladipo, J.O., Akinwumiju, A.S., Aboyeji, O.S., Adelodun, A.A., 2021. Comparison between fuzzy logic and water quality index methods: A case of water quality assessment in Ikare community, Southwestern Nigeria. Environmental Challenges 3, 100038.

Ramsar Convention, 2020. The List of Wetlands of International Importance.

Ruzbahani, M.S., Manager, N.P., 2013. Conservation of Iranian Wetlands.

Saaty, T.L., 2004. Decision making - the analytic hierarchy and network processes (AHP/ANP). Journal of systems science and systems engineering 13, 1-35.

Saaty, T.L., 2003. Decision-making with the AHP: Why is the principal eigenvector necessary. European journal of operational research 145, 85-91.

Saaty, T.L., 2001. Fundamentals of the analytic hierarchy process, in: The Analytic Hierarchy Process in Natural Resource and Environmental Decision Making. Springer, pp. 15-35.

Salimi, S., Almuktar, S.A.A.A.N., Scholz, M., 2021. Impact of climate change on wetland ecosystems: A critical review of experimental wetlands. Journal of Environmental Management 286, 112160.

Sarkar, S., Parihar, S.M., Dutta, A., 2016. Fuzzy risk assessment modelling of East Kolkata Wetland Area: A remote sensing and GIS based approach. Environmental Modelling \& Software 75, 105-118.

Seyedmohammadi, J., Sarmadian, F., Jafarzadeh, A.A., Ghorbani, M.A., Shahbazi, F., 2018. Application of SAW, TOPSIS and fuzzy TOPSIS models in cultivation priority planning for maize, rapeseed and soybean crops. Geoderma 310, 178-190.

Shwetank, Suhas, Chaudhary, J.K., 2020. A Comparative Study of Fuzzy Logic and WQI for Groundwater Quality Assessment. Procedia Computer Science 171, 1194-1203.

Spencer, C., Robertson, A.I., Curtis, A., 1998. Development and testing of a rapid appraisal wetland condition index in south-eastern Australia. Journal of Environmental Management 54, 143-159.

Srđević, Z., Srđević, B., Suvočarev, K., Galamboš, L., 2020. Hybrid Constructed Wetland Selection as a Group Decision-Making Problem. Water Resources Management 34, 295-310.

Stein, E.D., Fetscher, A.E., Clark, R.P., Wiskind, A., Grenier, J.L., Sutula, M., Collins, J.N., Grosso, C., 2009. Validation of a wetland rapid assessment method: use of EPA's level 1-2-3 framework for method testing and refinement. Wetlands 29, 648.

Stryszowska-Hill, K.M., Benson, C.E., Carberry, B., Twiss, M.R., Langen, T.A., 2019. Performance of wetland environmental quality assessment indicators at evaluating palustrine wetlands in northeastern New York State. Ecological Indicators 98, 743-752.

Sun, B., Tang, J., Yu, D., Song, Z., Wang, P., 2019. Ecosystem health assessment: A PSR analysis combining AHP and FCE methods for Jiaozhou Bay, China1. Ocean \& Coastal Management 168, 4150.

Thapa, S., Wang, L., Koirala, A., Shrestha, S., Bhattarai, S., Aye, W.N., 2020. Valuation of Ecosystem Services from an Important Wetland of Nepal: A Study from Begnas Watershed System. WETLANDS 40, 1071-1083.

Wanda, E.M.M., Mamba, B.B., Msagati, T.A.M., Msilimba, G., 2016. Determination of the health of Lunyangwa wetland using Wetland Classification and Risk Assessment Index. Physics and Chemistry of the Earth, Parts A/B/C 92, 52-60.

Wang, K., 2001. Computational Intelligence in Agile Manufacturing Engineering. Agile Manufacturing The 
21st Century Competitive Strategy, Oxford, UK: Elsevier Science Ltd 297-315.

Wilde, F., 2006. Temperature 6.1. USGS Field Manual. Retrieved from https://pubs.er.usgs.gov/publication/twri09A6.1.

Wu, C., Chen, W., Cao, C., Tian, R., Liu, D., Bao, D., 2018. Diagnosis of wetland ecosystem health in the Zoige Wetland, Sichuan of China. Wetlands 38, 469-484.

Xu, L., Ao, C., Mao, B., Cheng, Y., Sun, B., Wang, J., Liu, B., Ma, J., 2020. Which is more Important, Ecological Conservation or Recreational Service? Evidence from a Choice Experiment in Wetland Nature Reserve Management. Wetlands 40, 2381-2396.

Yepes, G.Y.F., Pérez, J.F.B., 2019. State of conservation index for high Andean wetlands. Journal for nature conservation $49,45-53$. 
Figures

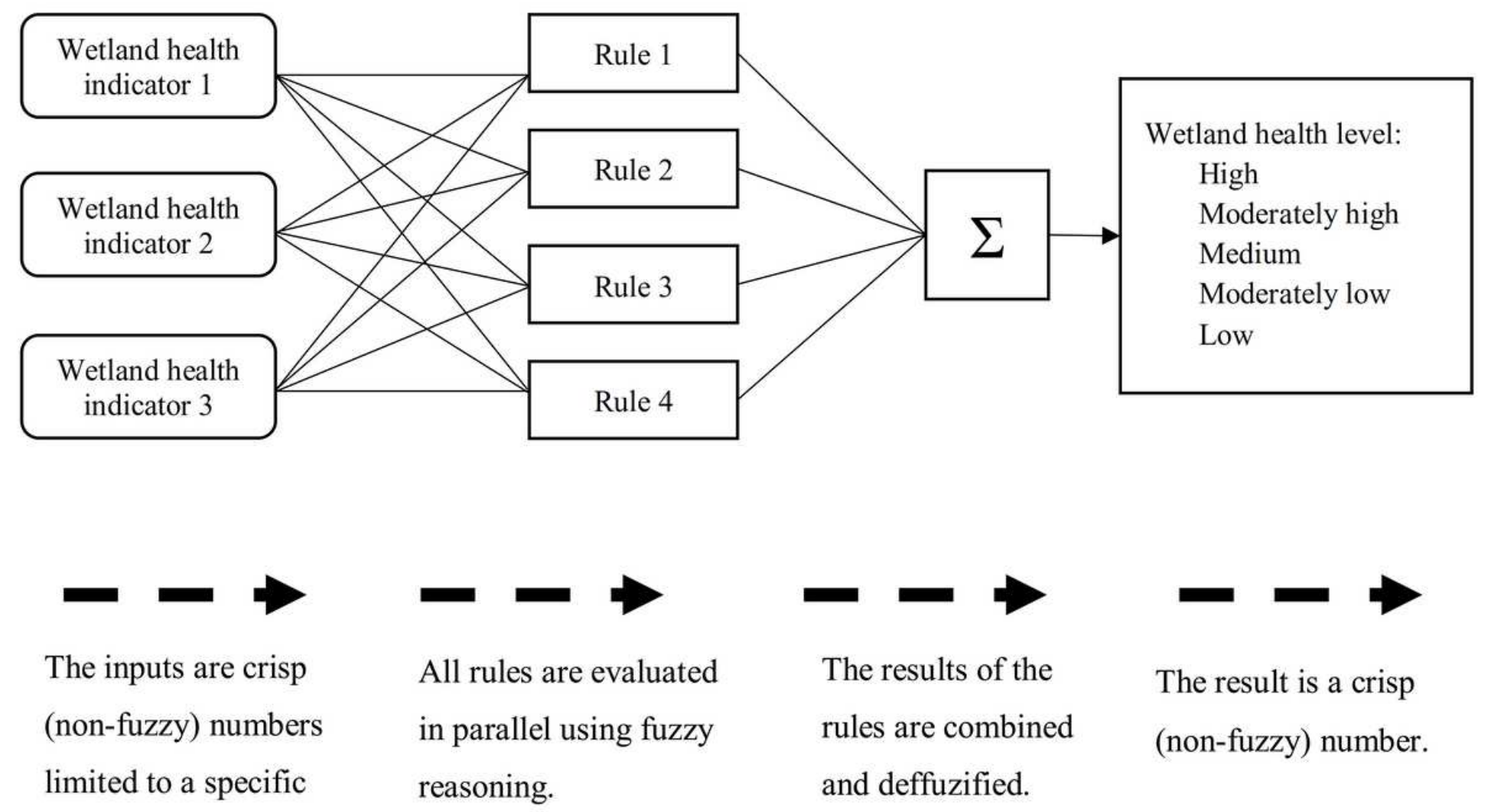

\section{Figure 1}

Input-output map for the wetland health level problem in a fuzzy inference system. 

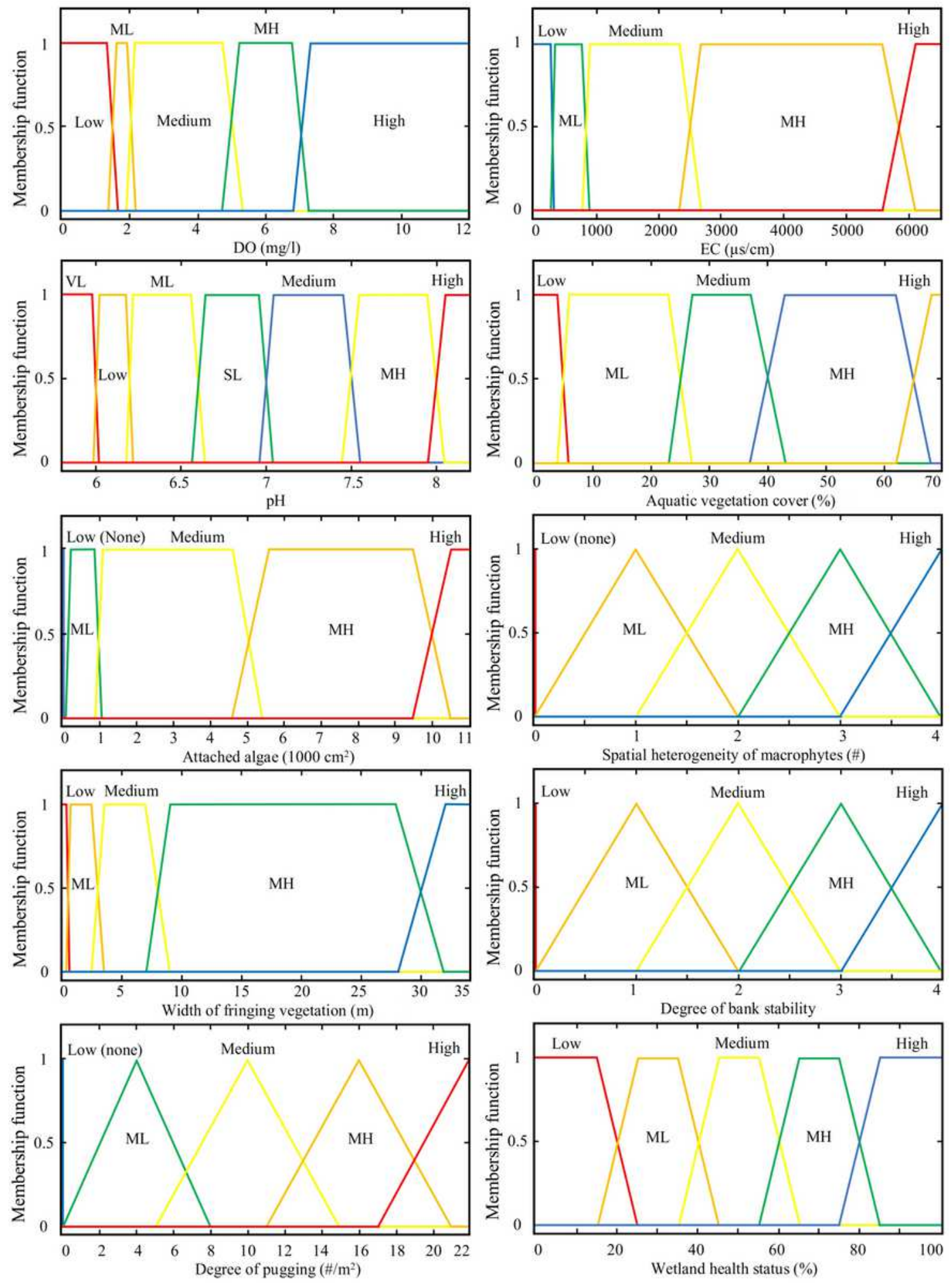

Figure 2

Linguistic variables and membership functions of the input and output variables 


\section{Field measurements}

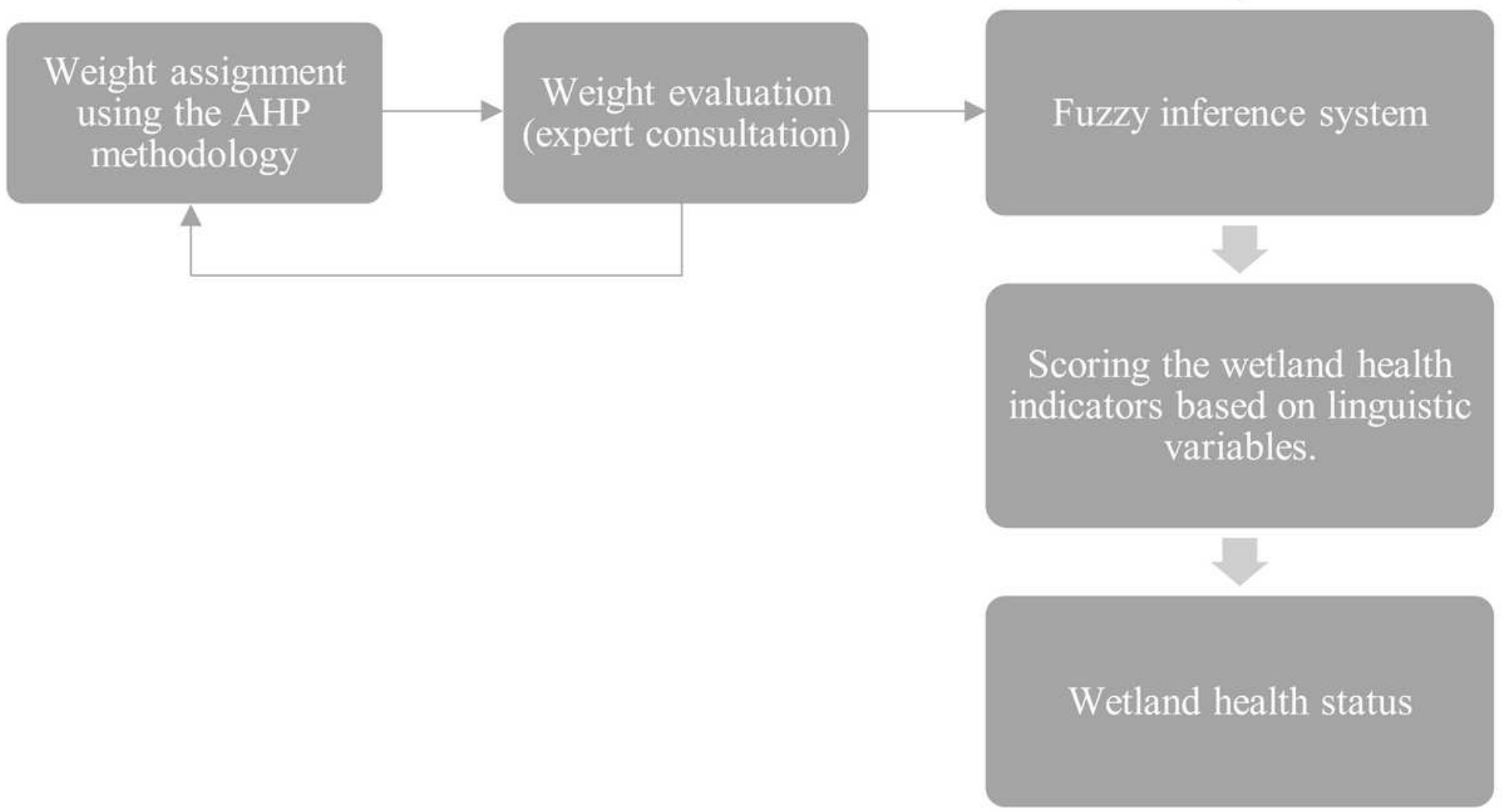

\section{Figure 3}

The framework of the fuzzy logic-based wetland risk assessment approach 

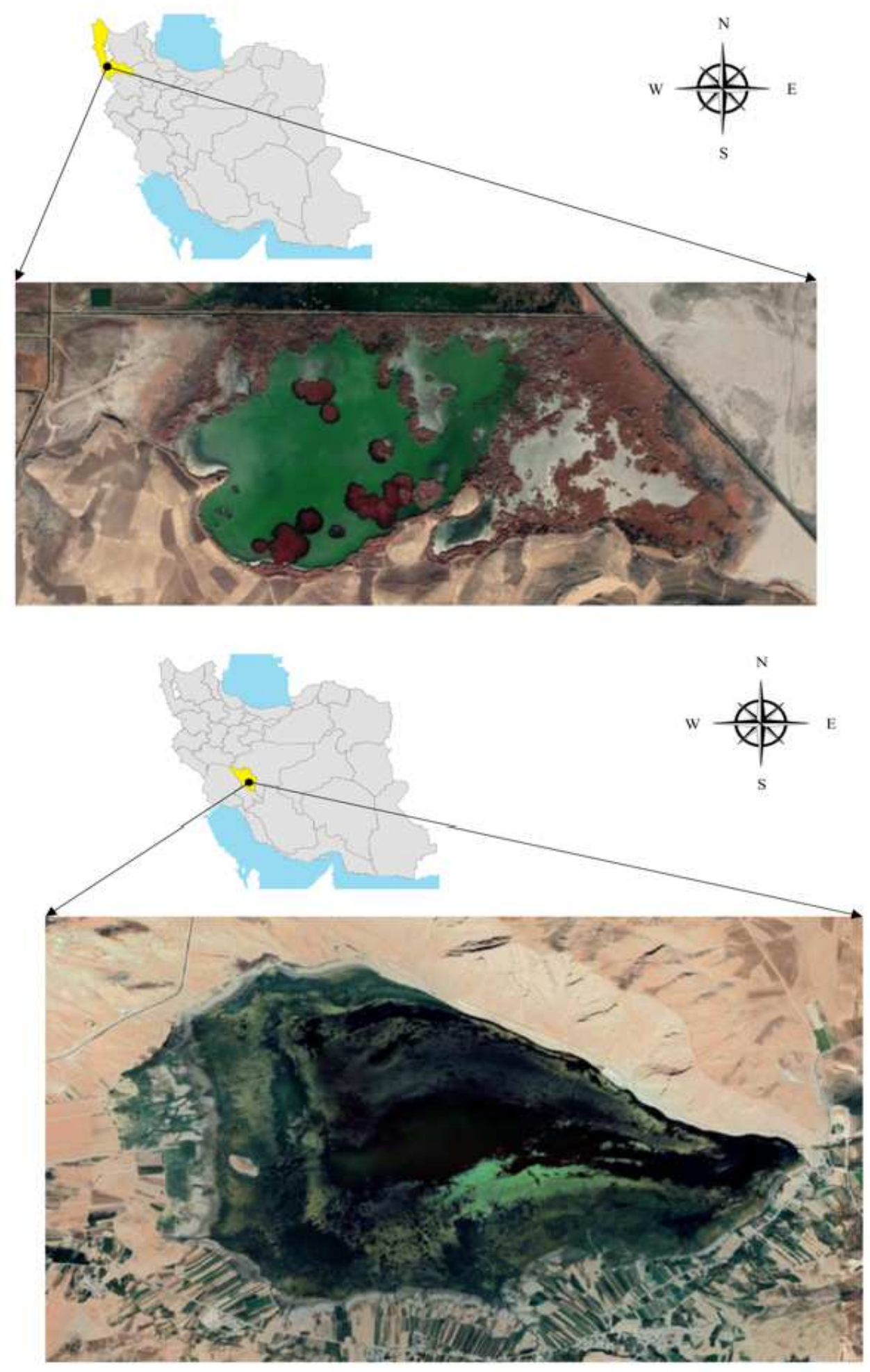

\section{Figure 4}

(a) Satellite view of the Kani Barazan wetland (b) Satellite view of the Choghakhor wetland Note: The designations employed and the presentation of the material on this map do not imply the expression of any opinion whatsoever on the part of Research Square concerning the legal status of any country, territory, city or area or of its authorities, or concerning the delimitation of its frontiers or boundaries. This map has been provided by the authors. 

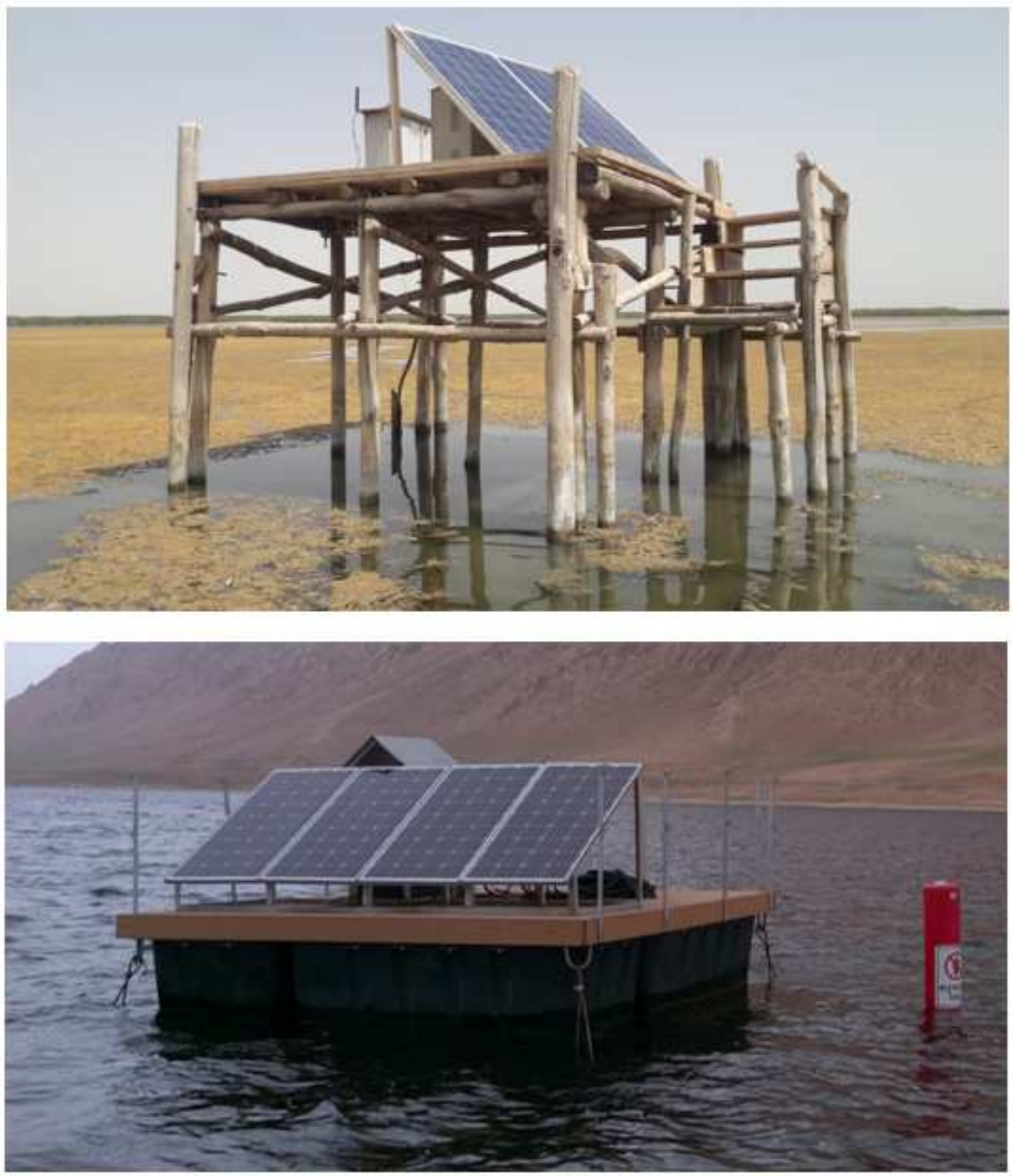

Figure 5

(a) The online monitoring station in the Kani Barazan wetland (b) The online monitoring station in the Choghakhor wetland 


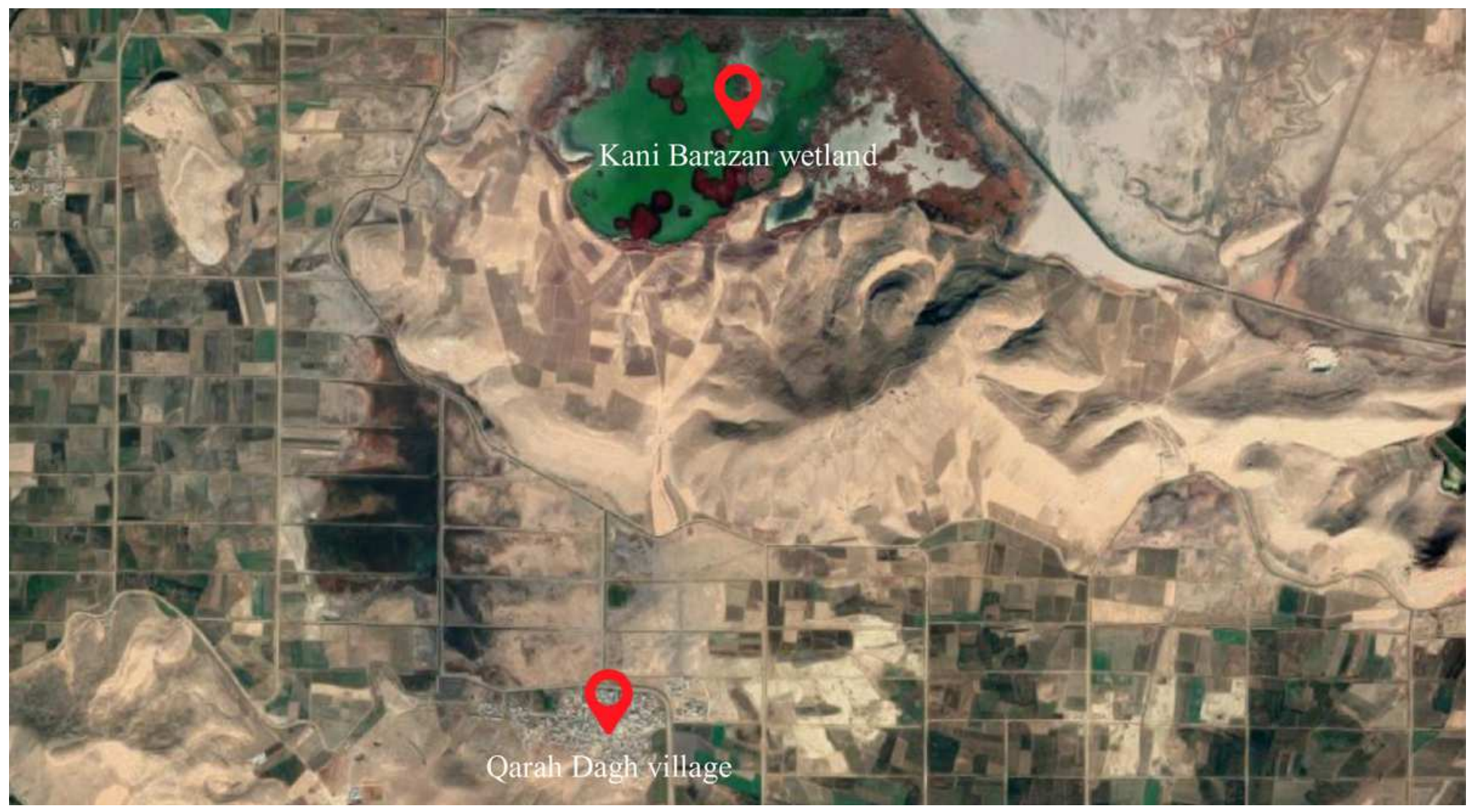

Figure 6

Relative location of the Kani Barazan wetland and Qarah Dagh village Note: The designations employed and the presentation of the material on this map do not imply the expression of any opinion whatsoever on the part of Research Square concerning the legal status of any country, territory, city or area or of its authorities, or concerning the delimitation of its frontiers or boundaries. This map has been provided by the authors. 

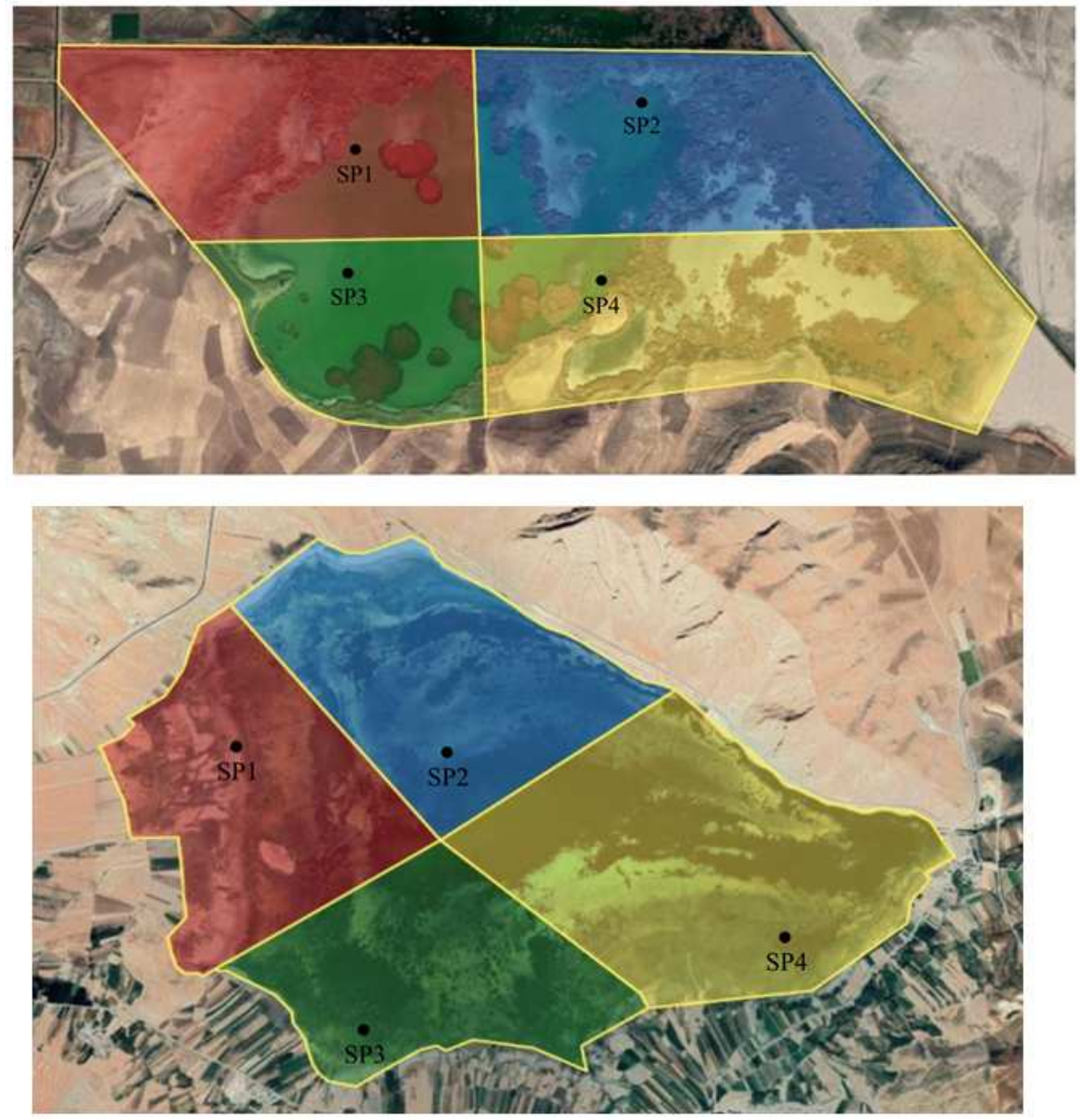

\section{Figure 7}

(a) Four parts of the Kani Barazan with water sampling points (b) Four parts of the Choghakhor wetland with water sampling points Note: The designations employed and the presentation of the material on this map do not imply the expression of any opinion whatsoever on the part of Research Square concerning the legal status of any country, territory, city or area or of its authorities, or concerning the delimitation of its frontiers or boundaries. This map has been provided by the authors. 


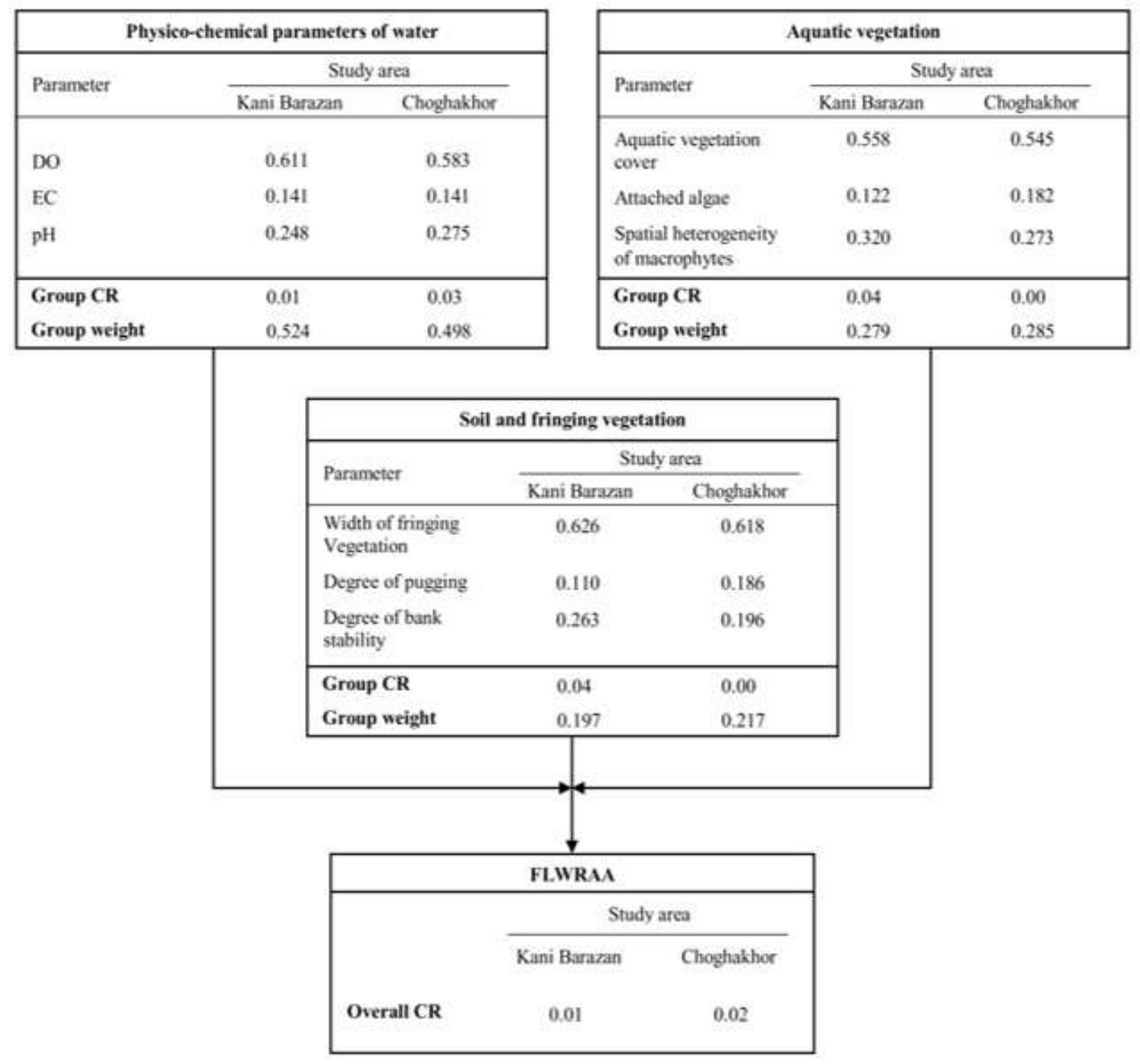

\section{Figure 8}

Optimized weights used in the FLWRAA obtained by the AHP methodology. 


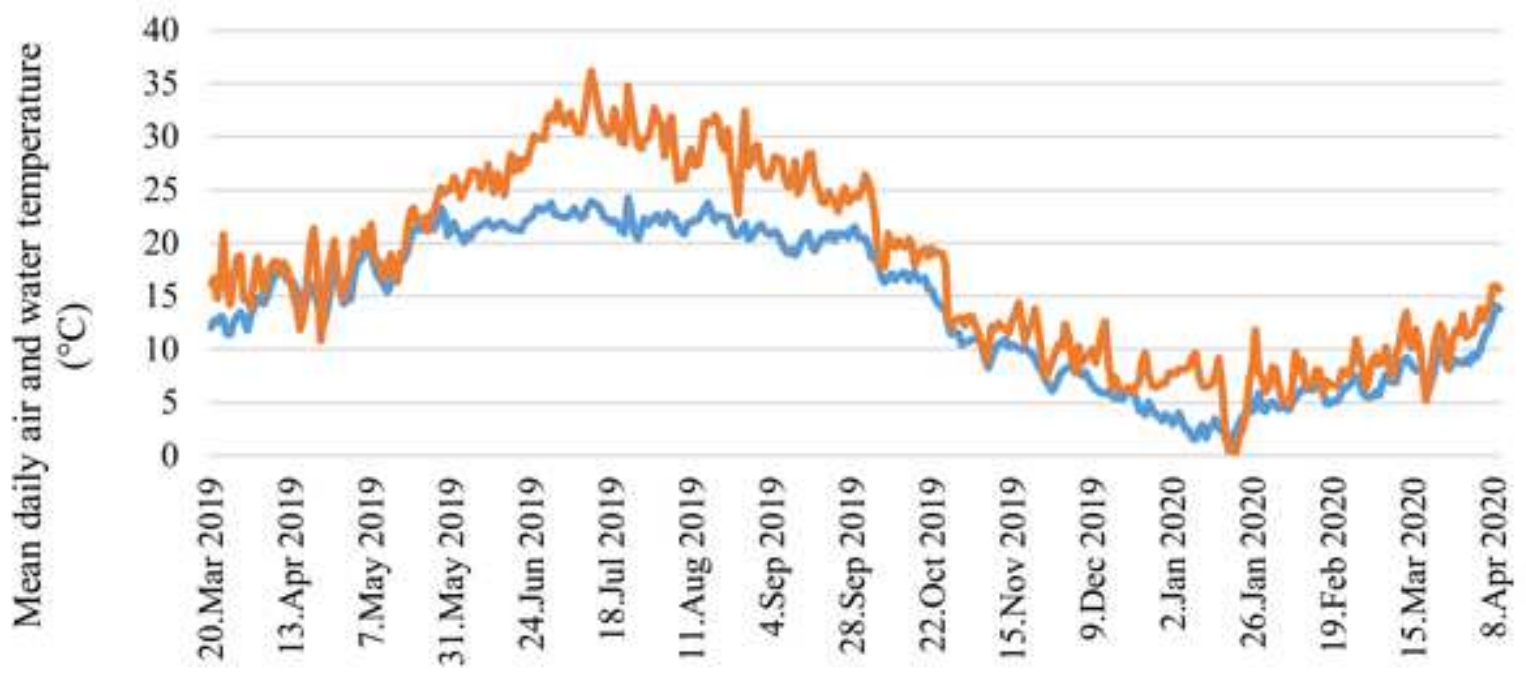

Date

Mean daily water temperature $\quad$ Mean daily air temperature

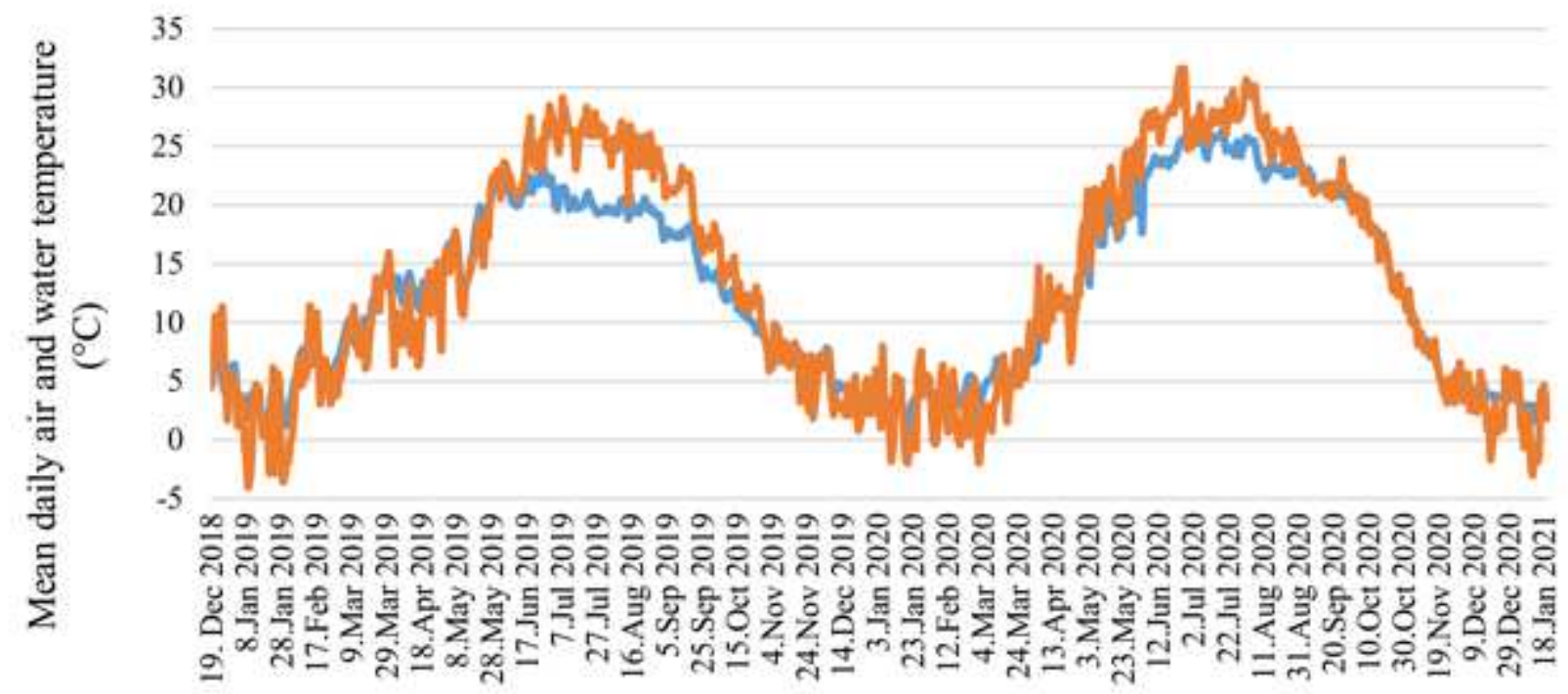

Date

Mean Daily Water Temperature _ Mean Daily Air Temperature

\section{Figure 9}

(a) The relationship between mean daily air and water temperature in the Kani Barazan wetland between March 2019 and April 2020. (b) Relationship between mean daily air and water temperature in the Choghakhor wetland between December 2018 and January 2021 


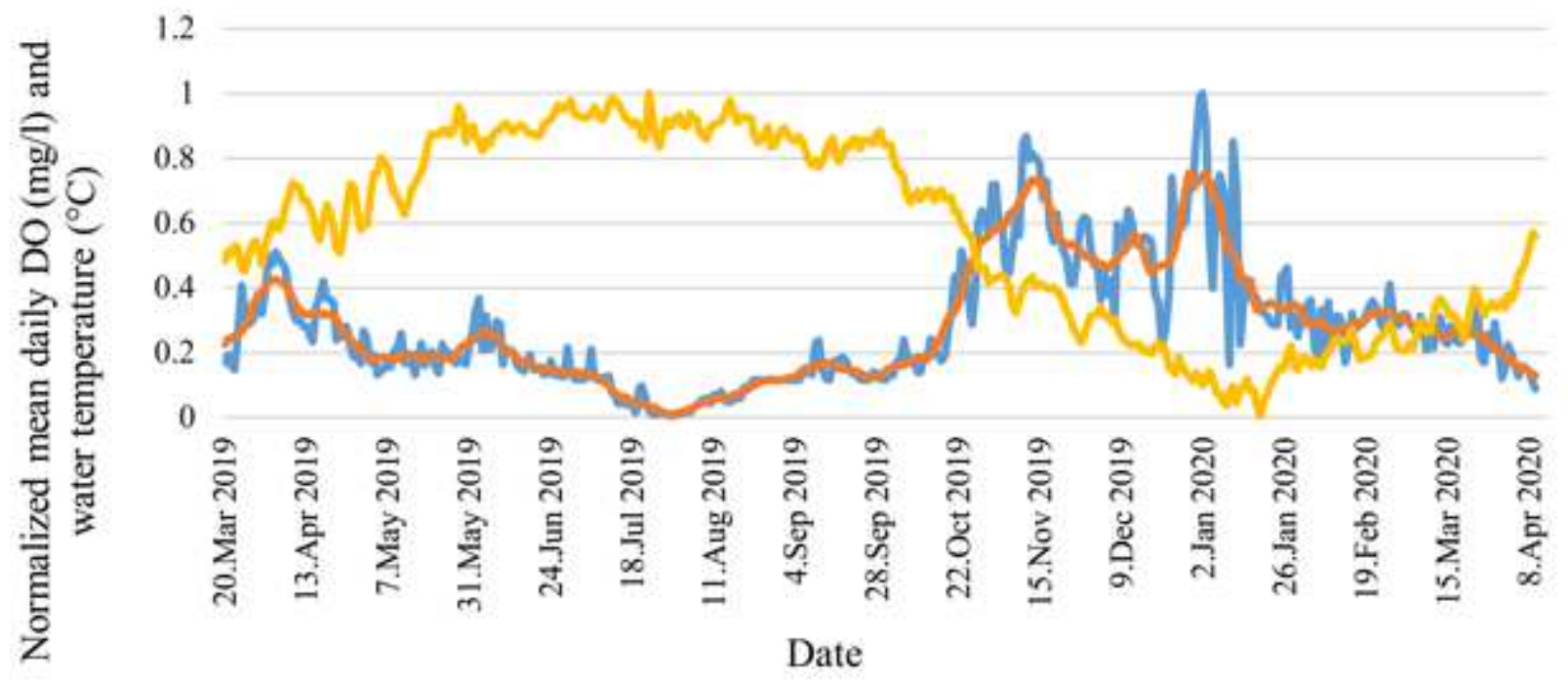

- Normalized mean daily DO $\quad$ Smoothed mean daily DO

Normalized mean daily water temperature

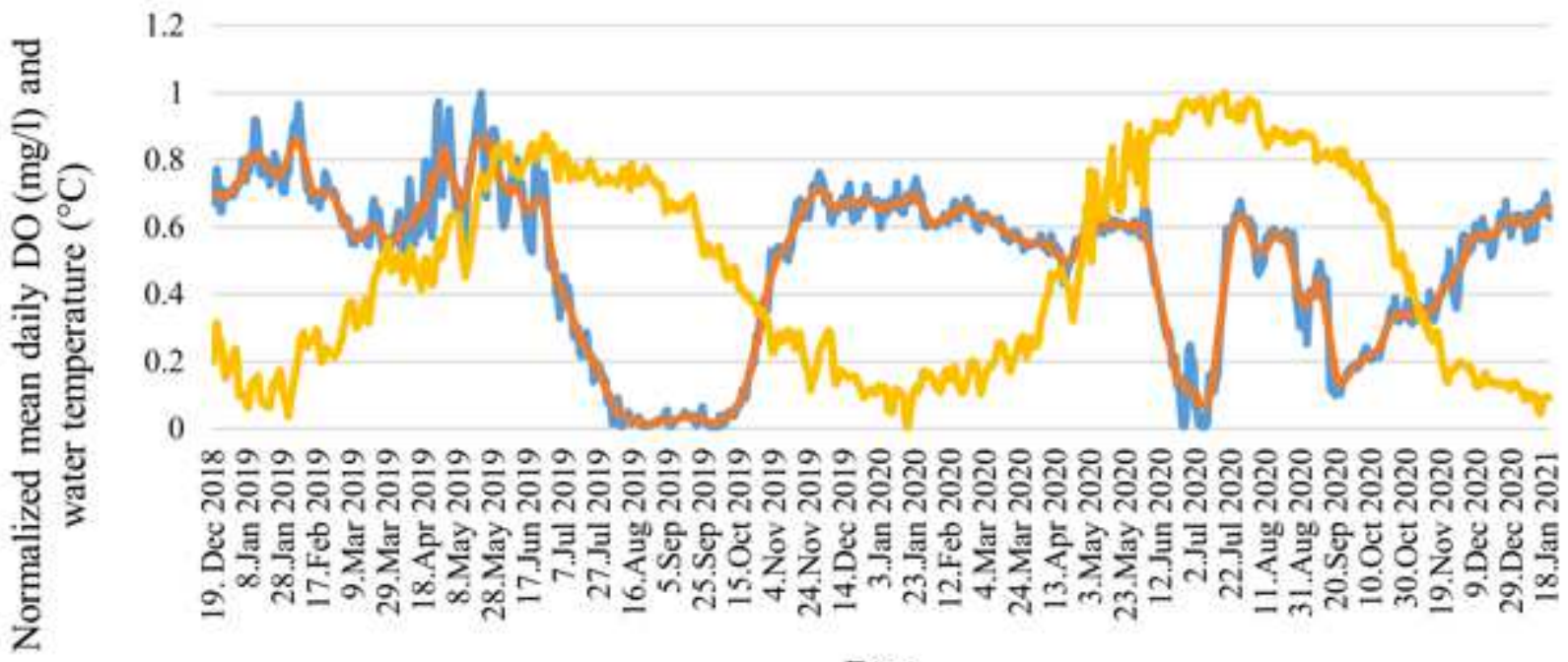

Date

- Normalized mean daily DO Smoothed mean daily DO

Normalized mean daily water temperature

Figure 10

(a) The relationship between mean daily DO and water temperature in the Kani Barazan wetland between March 2019 and April 2020. (b) The relationship between mean daily DO and water temperature in the Choghakhor wetland between December 2018 and January 2021 


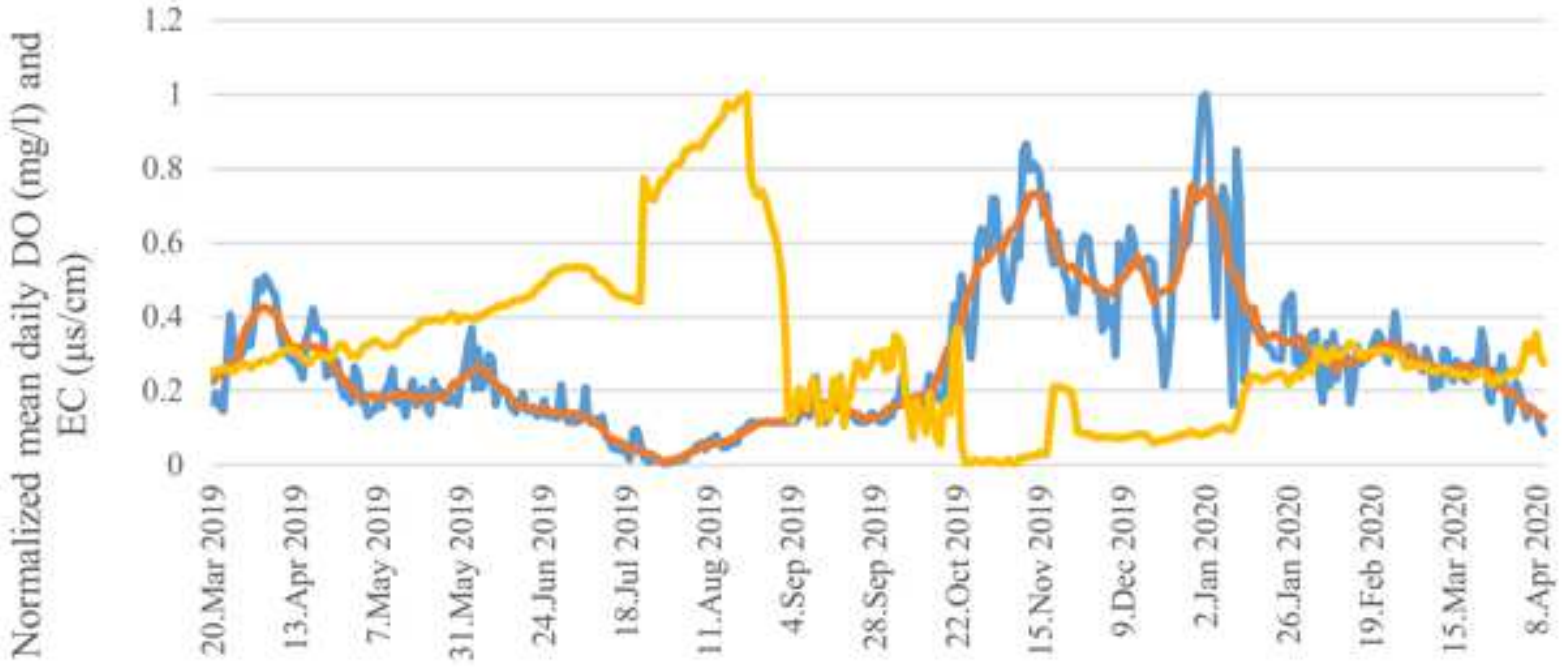

Date

Normalized mean daily DO $\longrightarrow$ Smoothed mean daily DO $=$ Nomalized mean daily EC

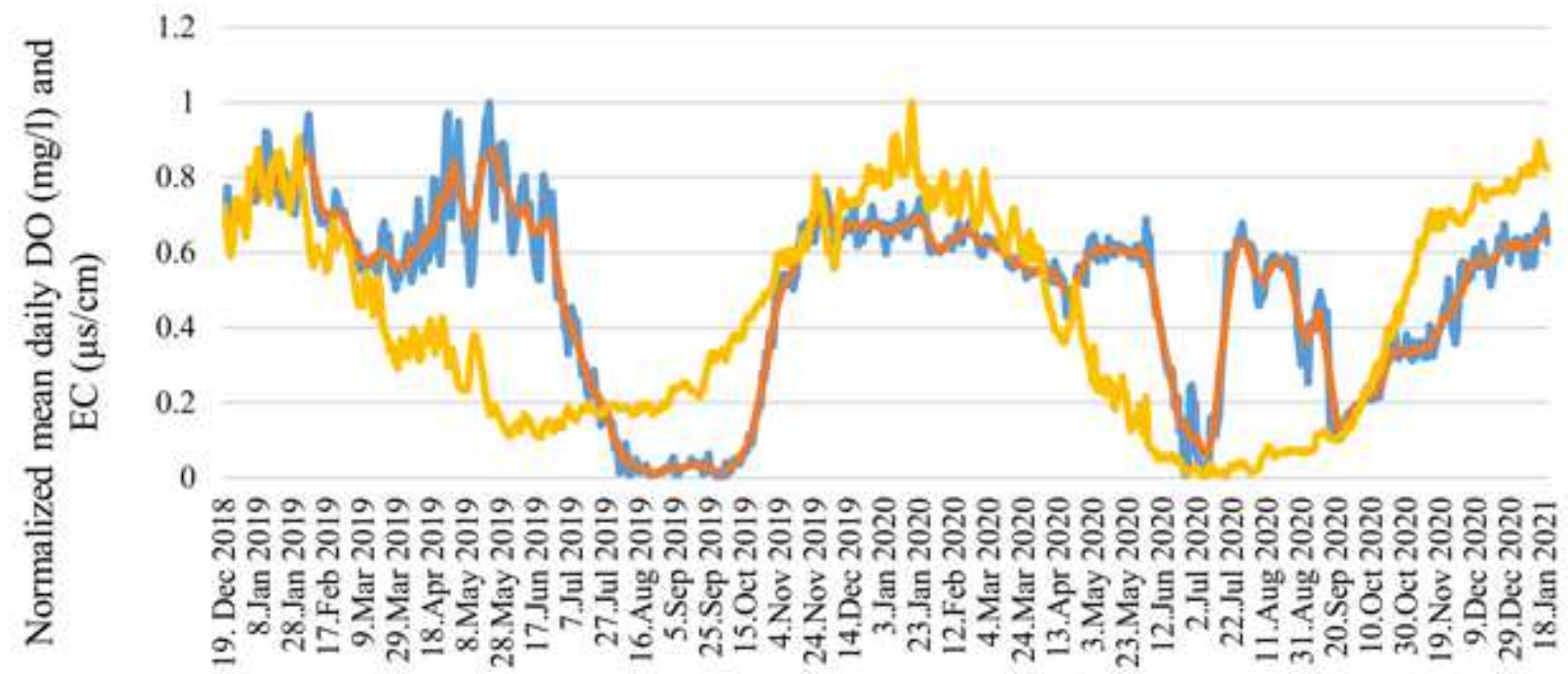

Date

Normalized mean daily DO $\longrightarrow$ Smoothed mean daily DO $\longrightarrow$ Normalized mean daily EC

\section{Figure 11}

(a) The relationship between mean daily DO and EC in the Kani Barazan wetland between March 2019 and April 2020. (b) The relationship between mean daily DO and EC in the Choghakhor wetland between December 2018 and January 2021. 


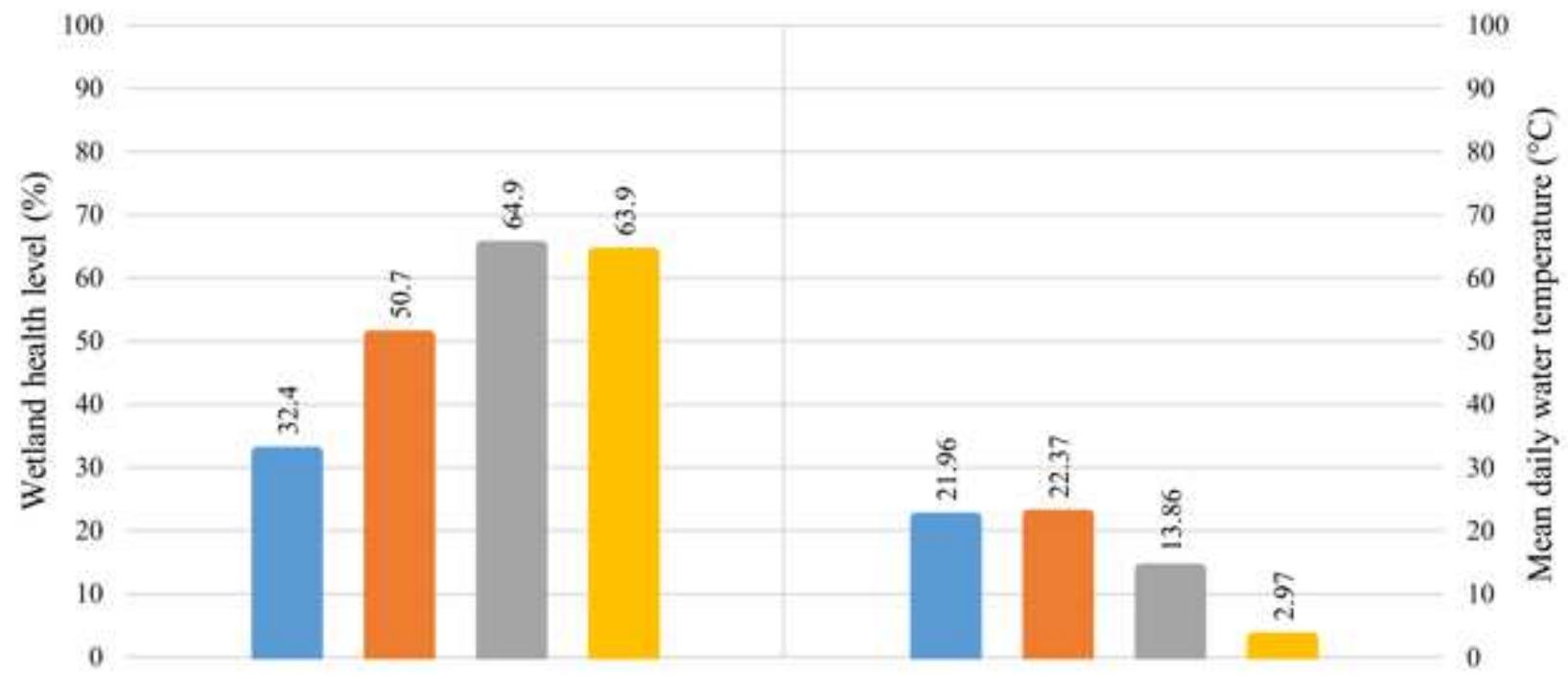

Date

30-Jul-19 (Lowest DO) 22-Aug-19 (Highest EC) 25-Oct-19 (Lowest EC) 2-Jan-20 (Highest DO)

Figure 12

A comparison between wetland health levels (part 3) based on DO and EC extreme values and mean daily water temperature. 


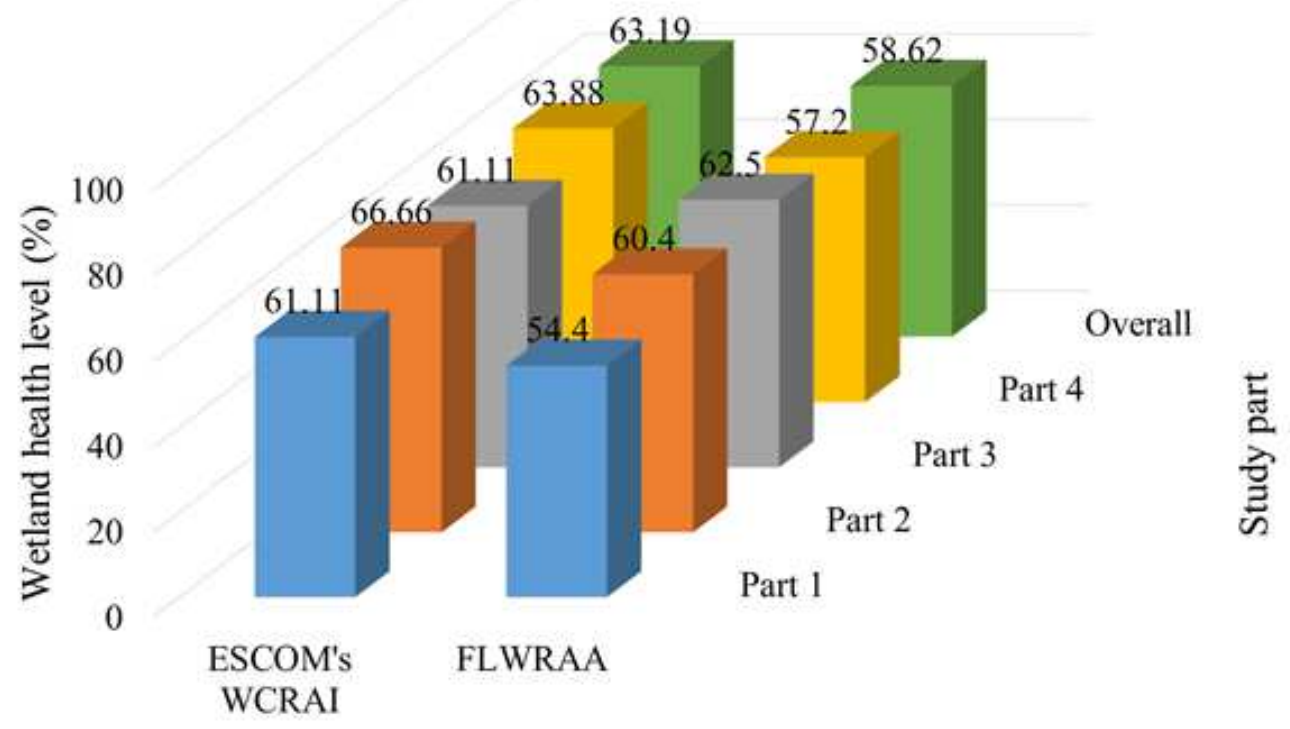

Risk assessment framework

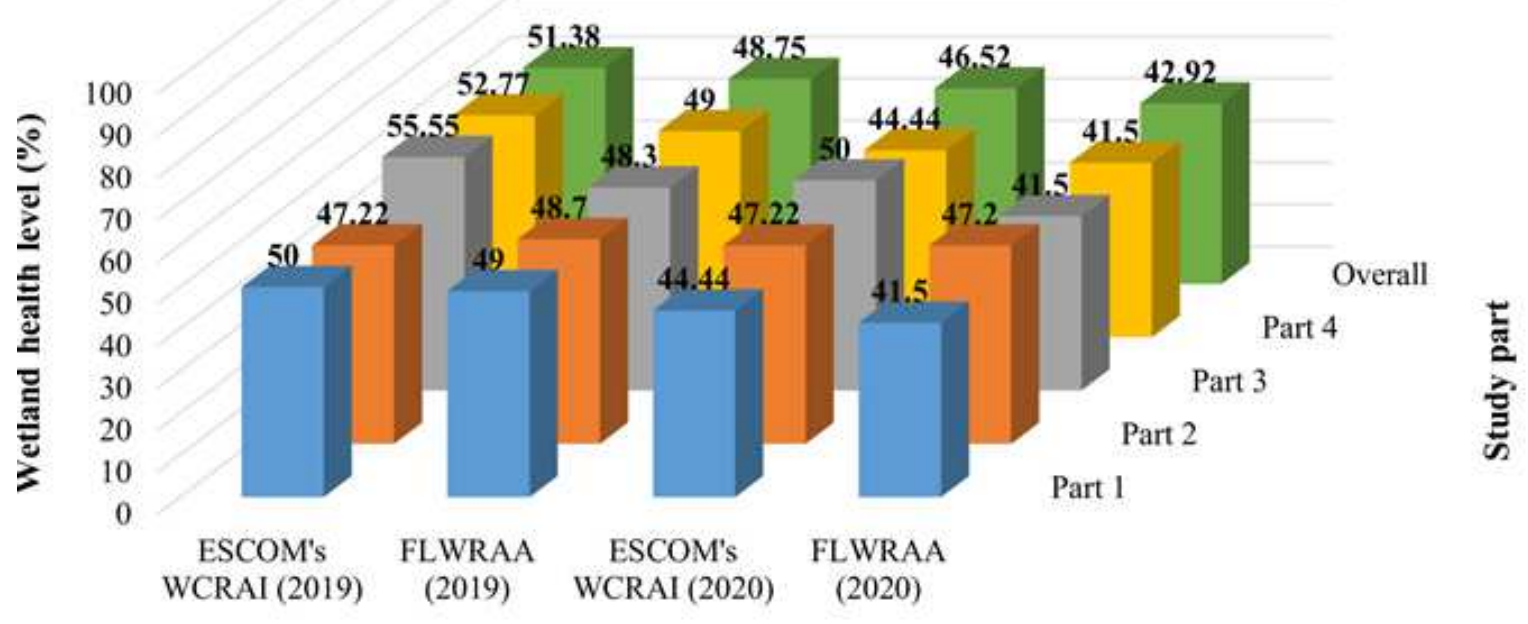

Risk assessment framework

Figure 13

(a) Results for health level of the Kani Barazan wetland (b) Results for health level of the Choghakhor wetland in 2019 and 2020 